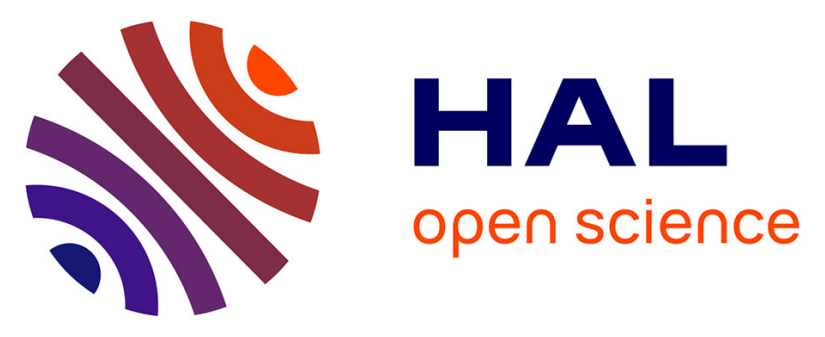

\title{
Increasing the efficiency of magnetic heterogeneous Fenton catalysts with a simple halogen visible lamp
}

Nassira Ferroudj, Delphine Talbot, Aude Michel, Anne Davidson, Sébastien

Abramson

\section{- To cite this version:}

Nassira Ferroudj, Delphine Talbot, Aude Michel, Anne Davidson, Sébastien Abramson. Increasing the efficiency of magnetic heterogeneous Fenton catalysts with a simple halogen visible lamp. Journal of Photochemistry and Photobiology A: Chemistry, 2017, 338, pp.85-95. 10.1016/j.jphotochem.2017.01.029 . hal-01525893

\section{HAL Id: hal-01525893 https: / hal.sorbonne-universite.fr/hal-01525893}

Submitted on 15 Jun 2017

HAL is a multi-disciplinary open access archive for the deposit and dissemination of scientific research documents, whether they are published or not. The documents may come from teaching and research institutions in France or abroad, or from public or private research centers.
L'archive ouverte pluridisciplinaire $\mathbf{H A L}$, est destinée au dépôt et à la diffusion de documents scientifiques de niveau recherche, publiés ou non, émanant des établissements d'enseignement et de recherche français ou étrangers, des laboratoires publics ou privés. 


\section{Increasing the Efficiency of Magnetic Heterogeneous Fenton Catalysts with a Simple Halogen Visible Lamp}

Nassira Ferroudj*1 ${ }^{1}$, Delphine Talbot ${ }^{2}$, Aude Michel $^{2}$, Anne Davidson ${ }^{3}$, Sébastien Abramson ${ }^{2}$

${ }^{1}$ : Laboratoire de Génie Chimique et Environnement de Skikda, Université du 20 Août 1955 de Skikda, BP 26 Route d'El Hadaiek, Skikda, Algeria

2 : Laboratoire de PHysico-chimie des Electrolytes et Nanosystèmes InterfaciauX (PHENIX UMR 7195, UPMC-CNRS), Université Pierre et Marie Curie, 4 place Jussieu, 75252 Paris, France

${ }^{3}$ : Laboratoire de Réactivité de Surface (LRS-UMR 7197, UPMC-CNRS), Université Pierre et Marie Curie, 4 place Jussieu, 75252 Paris, France

*Corresponding author : fernassira@yahoo.fr 


\begin{abstract}
:
The effect of a simple visible halogen lamp was studied in the Fenton-type oxidation of three model aqueous pollutants differing in their structure and electrostatic charge, methylorange (MO), methylene blue (MB) and paranitrophenol (PNP), using maghemite nanoparticles $(\gamma-$ $\mathrm{Fe}_{2} \mathrm{O}_{3} \mathrm{NP}$ ), or maghemite/silica nanocomposite microspheres $\left(\gamma-\mathrm{Fe}_{2} \mathrm{O}_{3} / \mathrm{SiO}_{2}\right.$ MS) as heterogeneous catalysts. These materials, which were fully characterized, differ in size, morphology, porosity and microstructure, although their catalytic activity is related to the same $\gamma-\mathrm{Fe}_{2} \mathrm{O}_{3}$ nanoparticles. Both have a strong magnetic susceptibility, but only the MS catalyst can be easily recovered by magnetic settlement. Whatever the catalyst, the pollutant tested, or the experimental conditions used, much better decolorization rates and mineralization efficiencies were recorded under illumination by visible light in comparison to the same tests in the dark. The large range of experimental conditions tested enabled us to propose a mechanism for photocatalytic activity. Experiments of long-term stability showed that the MS catalyst, although generally less active than the NP catalyst, retained almost all of its activity after five repeated experiments under visible light. The good stability of this catalyst was also confirmed by the low level of iron leaching, making it suitable candidate for an application as photo-Fenton catalyst in industrial wastewater treatment.
\end{abstract}

\title{
Keywords:
}

Heterogeneous photo-Fenton, Iron oxide nanoparticles, Magnetic nanocomposite microspheres, Visible light irradiation, Wastewater. 


\section{Introduction}

Nowadays, advanced oxidation processes (AOPs) are becoming increasingly important for wastewater treatment technologies, especially for poorly biodegradable contaminants.[1-5] The common feature of these processes is the production of extremely reactive and unselective radical oxygen species, especially the highly oxidizing hydroxyl radicals $\left(\mathrm{HO}^{\circ}\right)$, which are able to degrade even the most recalcitrant molecules into biodegradable compounds, or mineralize them into $\mathrm{CO}_{2}, \mathrm{H}_{2} \mathrm{O}$ and inorganic ions.[3] AOPs can be divided into different groups based on how the radicals are produced. One may mention the sonochemical processes, the radiolysis, the electrochemical methods, and the purely chemical processes which include the Fenton-type reactions $\left(\mathrm{H}_{2} \mathrm{O}_{2} / \mathrm{Fe}\right.$ catalyst). Nevertheless, one of the most important classes of AOPs is constituted by the photochemical processes, such as water, $\mathrm{H}_{2} \mathrm{O}_{2}$ and/or $\mathrm{O}_{3}$ photolysis $\left(\mathrm{h} v / \mathrm{H}_{2} \mathrm{O}, \mathrm{h} v / \mathrm{H}_{2} \mathrm{O}_{2}, \mathrm{~h} v / \mathrm{O}_{3}, \mathrm{~h} v / \mathrm{H}_{2} \mathrm{O}_{2} / \mathrm{O}_{3}\right)$, heterogeneous photocatalysis ( $\mathrm{h} v / \mathrm{TiO}_{2}$ catalyst), and the photo-Fenton process $\left(\mathrm{h} v / \mathrm{H}_{2} \mathrm{O}_{2} / \mathrm{Fe}\right.$ catalyst).[5,6] Their generally high efficiency is due to the assistance of UV or visible light irradiation, which is directly or indirectly responsible for the production of the radicals. UV light is usually used in the photochemical processes, because of its large energy which is able to induce the direct photolysis of an oxidant $\left(\mathrm{H}_{2} \mathrm{O}_{2}, \mathrm{O}_{3}, \mathrm{O}_{2}, \mathrm{H}_{2} \mathrm{O} \ldots\right)$, or to activate a semiconducting catalyst such as $\mathrm{TiO}_{2}$, leading to the generation of large amount of oxygen radicals. However, the photodegradation under UV irradiation is limited for industrial utilization, since natural UV occupies only $3-5 \%$ of the solar light energy that reaches earth, while artificial UV light generators consume large quantities of electrical power and can be expensive and unstable. Recently, much effort has been done to expand the response of the photodegradation processes to visible light irradiation, in replacement or addition to UV-light. Nevertheless, water-treatment by direct visible-light photolysis of an oxidant is unfavourable, since the rate of photolytic decomposition of the oxidants to oxygen radicals is very slow. To overcome this drawback, it is thus necessary to add a photocatalyst. [7] In recent years, there has been an extensive interest in the use of semiconductors in photochemical degradation. Among them, $\mathrm{TiO}_{2}$ has been widely used as an effective photocatalyst for environment purification since it can decompose a large number of pollutants, [6-10] but its wide bandgap $(\sim 3,2 \mathrm{eV})$ limits its application to UV light irradiation. To the contrary, iron oxide particles $\left(\mathrm{Fe}_{3} \mathrm{O}_{4}, \mathrm{Fe}_{2} \mathrm{O}_{3}, \mathrm{FeOOH} \ldots\right)$ are suitable candidates to be used as visible-light photocatalysts for water treatment. Indeed iron oxides have a relatively small bandgap $\left(\sim 2,1 \mathrm{eV}\right.$ for $\left.\mathrm{Fe}_{2} \mathrm{O}_{3}\right)$ which is appropriate for receiving visible light, and the electron-hole pair may generates 
radical oxygen species in the same way as $\mathrm{TiO}_{2}$.[11-13] In addition, compared with $\mathrm{TiO}_{2}$, iron oxide presents the advantages to be non-toxic and inexpensive.[14,15] However it has been reported that iron oxides are relatively inefficient visible-light photocatalysts in the absence of additional oxidant,[11-13] while they are much more active as heterogeneous photo-Fenton catalysts, $i$. e.when $\mathrm{H}_{2} \mathrm{O}_{2}$ is added as additional oxidant to generate the oxygen reactive species.[13,16] To explain this result, it has been proposed that large amounts of $\mathrm{HO}^{\circ}$, are generated from $\mathrm{H}_{2} \mathrm{O}_{2}$ at the surface of the iron oxide in the presence of light.[17-19]

Although the photo-Fenton process is also efficient in homogeneous phase at $\mathrm{pH}=3$ (i.e. with dissolved $\mathrm{Fe}^{2+}$ or $\mathrm{Fe}^{3+}$ as catalyst), the use of iron oxides as heterogeneous catalyst provides the possibility to recover and reuse the catalyst and to operate in a broader $\mathrm{pH}$ range.[20] In spite of these advantages, there is a relatively small number of studies on the use of iron oxides as photo-Fenton catalysts under visible light.[13, 17-29] These studies have clearly shown that the efficiency of the iron oxide $/ \mathrm{H}_{2} \mathrm{O}_{2}$ system in the degradation of various model pollutants is considerably increased through visible light irradiation, which might be slightly more efficient than UV light irradiation.[27] However the impact of the experimental conditions on the efficiency of visible light irradiation is still poorly understood. This article aims to highlight the parameters affecting the efficiency of visible light irradiation in a heterogeneous photo-Fenton process, using maghemite $\left(\gamma-\mathrm{Fe}_{2} \mathrm{O}_{3}\right)$ nanoparticles (NP) as photocatalyst. The effect of the visible light irradiation on the activity of this catalyst is studied for a large range of conditions obtained by varying several parameters such as the presence of a silica support, the nature of the model pollutant, the $\mathrm{pH}$, the $\mathrm{H}_{2} \mathrm{O}_{2}$ concentration, and the amount of catalyst.The choice of $\gamma-\mathrm{Fe}_{2} \mathrm{O}_{3}$ nanoparticles has been dictated by several considerations. First, $\gamma-\mathrm{Fe}_{2} \mathrm{O}_{3}$ is characterized by a high magnetic susceptibility, which offers an additional advantage in terms of recovery and reusability of the catalyst. Indeed magnetic iron oxides can be easily separated and removed from solution by simply applying an external magnetic field with a magnet or an electromagnet.[31-33] Magnetic settlement by an appropriate magnetic field provides a convenient and low cost method for the separation of solid particles in a suspension, as it is well illustrated in sewage or drinking water plants with the Sirofloc ${ }^{\circledR}$ process.[34] Second, it has been shown that $\gamma-\mathrm{Fe}_{2} \mathrm{O}_{3}$ and $\mathrm{Fe}_{3} \mathrm{O}_{4}$ are the most active and stable iron oxide phases in photo-Fenton processes.[16] Compared with $\mathrm{Fe}_{3} \mathrm{O}_{4}, \gamma$ $\mathrm{Fe}_{2} \mathrm{O}_{3}$ nanoparticles are not submitted to oxidation, and are therefore more stable in water and air. Third, the $\gamma-\mathrm{Fe}_{2} \mathrm{O}_{3}$ nanoparticles used in this work have been thoroughly characterized and tested as Fenton catalyst in a previous publication. [35] 
Among the parameters which are studied here, the presence of silica $\left(\mathrm{SiO}_{2}\right)$ microspheres (MS) as a porous support for the $\gamma-\mathrm{Fe}_{2} \mathrm{O}_{3}$ nanoparticles is of primary importance. It has been demonstrated that the dispersion of the catalyst on a support may considerably improve its activity, due to an increase of the adsorption of the pollutant and/or to a decrease of the recombination of the created electron-hole pairs.[28] Moreover, catalyst leaching problem can be avoided by hosting the heterogeneous catalyst onto a support.[36] In the case of a magnetic catalyst, we have shown in addition that the presence of a support can favor the recovery of the catalyst by magnetic settlement.[35] To study how the efficiency of light irradiation is affected by the nature of the pollutant, we chose to compare the degradation of three aqueous model pollutants, methylene blue (MB), methyl orange (MO) and paranitrophenol (PNP), which can be distinguished in terms of their charge, their light absorption properties, and their chemical structure. Finally, a simple halogen lamp has been taken as source of visible light. We show that this simple and cheap lamp is able to considerably increase both the decolorization and mineralization rate of the pollutant solutions without detrimental impact on the stability of the heterogeneous catalyst.

\section{Experimental}

\subsection{Catalysts synthesis}

The synthesis of the catalysts has been already described in our previous paper. [35] Briefly, magnetite $\left(\mathrm{Fe}_{3} \mathrm{O}_{4}\right)$ NP were first prepared by the Massart's method, adding ammonia to an aqueous mixture of $\mathrm{FeCl}_{3}$ and $\mathrm{FeCl}_{2}$.[37] Then, the $\mathrm{Fe}_{3} \mathrm{O}_{4} \mathrm{NP}$ were oxidized to $\gamma-\mathrm{Fe}_{2} \mathrm{O}_{3}$ by successively adding $\mathrm{HNO}_{3}$ and $\mathrm{Fe}\left(\mathrm{NO}_{3}\right)_{3}$. [38-39] The $\gamma-\mathrm{Fe}_{2} \mathrm{O}_{3} \mathrm{NP}$ were finally obtained as an aqueous acidic dispersion with a high colloidal stability, also called ferrofluid. The $\gamma-\mathrm{Fe}_{2} \mathrm{O}_{3}$ NP were supported on the surface of porous silica microspheres via a protocol inspired from the method originally described by Andersson et al..[35,40] Briefly,a magnetic sol containing the $\gamma-\mathrm{Fe}_{2} \mathrm{O}_{3} \mathrm{NP}$ and a silica precursor (Tetraethoxysilane, TEOS) in acidic medium was added dropwise to an organic phase composed of a vegetable oil (usually commercial rapeseed oil) and a commercial emulsifier (Arlacel P135 from Uniquema), under stirring. The water-in-oil emulsion thus formed was transferred into a Büchner flask, and the ethanol formed by the hydrolysis of TEOS was evaporated from the dispersed phase under reduced pressure, which led to a rapid condensation of TEOS in silica in each water droplet. The emulsion was then broken by addition of a large amount of acetone. The silica MS containing the $\gamma-\mathrm{Fe}_{2} \mathrm{O}_{3} \mathrm{NP}$ were washed several times with acetone and water, and dried at $70{ }^{\circ} \mathrm{C}$. Finally, the beads were 
calcined in an oven under air at $400{ }^{\circ} \mathrm{C}$ for $18 \mathrm{~h}$ to remove any organic traces. In the following sections, the unsupported $\gamma-\mathrm{Fe}_{2} \mathrm{O}_{3}$ nanoparticles will be referred as the $\gamma-\mathrm{Fe}_{2} \mathrm{O}_{3} \mathrm{NP}$ catalyst, while the $\gamma-\mathrm{Fe}_{2} \mathrm{O}_{3}$ nanoparticles supported on the surface of the silica microspheres will be referred as the $\gamma-\mathrm{Fe}_{2} \mathrm{O}_{3} / \mathrm{SiO}_{2} \mathrm{MS}$ catalyst.

\subsection{Characterization of the catalysts}

Transmission electron microscopy (TEM) micrographs of the $\gamma-\mathrm{Fe}_{2} \mathrm{O}_{3} \mathrm{NP}$ and $\gamma-\mathrm{Fe}_{2} \mathrm{O}_{3} / \mathrm{SiO}_{2}$ MS catalysts were taken using a JEM JEOL $100 \mathrm{CX}$ microscope operating at $100 \mathrm{kV}$. In this aim, the MS were embedded in a resin (AGAR 100), which was then polymerised at $60^{\circ} \mathrm{C}$ during two days, and cut in $70 \mathrm{~nm}$ thin sections using a LEICA ULTRACUT UCT microtome apparatus. The MS catalysts were also observed by scanning electron microscopy (SEM) on a SEM-FEG Hitachi SU-70 apparatus. The images were taken in secondary electron mode with an accelerating voltage of $10 \mathrm{kV}$. Prior to analysis, the beads were coated with a thin shell of gold by sputter deposition. The size distribution of the particles was determined from TEM or SEM pictures analyzed using the Image $J$ software. The amount of $\gamma-\mathrm{Fe}_{2} \mathrm{O}_{3} \mathrm{NP}$ in the MS was determined by spectrophotometry. In this aim, a given weight of material was first introduced in an $\mathrm{HCl}$ aqueous solution $\left(4 \mathrm{~mol} \mathrm{~L}{ }^{-1}\right.$ ). After $48 \mathrm{~h}$ of stirring, the $\gamma-\mathrm{Fe}_{2} \mathrm{O}_{3} \mathrm{NP}$ were totally dissolved, and the iron concentration in the supernatant was analyzed by atomic absorption spectrophotometry (Perkin Elmer AA100 apparatus) and the weight fraction of $\gamma-\mathrm{Fe}_{2} \mathrm{O}_{3}$ in the beads, $\mathrm{w}_{\mathrm{Fe} 2 \mathrm{O} 3}$ was determined. A similar procedure was used to determine the amount of $\gamma$ $\mathrm{Fe}_{2} \mathrm{O}_{3} \mathrm{NP}$ dispersed in water. Magnetic characterizations of the NP and MS catalysts were respectively made at $25{ }^{\circ} \mathrm{C}$ on a vibrating sample magnetometer (home-made apparatus) and SQUID magnetometer (Quantum Design MPM-5S apparatus). The NP were analysed dispersed in water, whereas the MS were analysed in powdered form. XRD spectra of the powdered samples were recorded using a Phillips PW 1130 diffractometer. Data were collected from $2 \theta=10^{\circ}$ to $80^{\circ}$ in $0.1^{\circ}$ steps. The room-temperature UV-visible-NIR spectra of the powdered samples were recorded with a diffuse reflectance cell (internal sphere) in the range 200-2500 nm on a Varian Cary 400 spectrometer (Teflon as a blank). The pure $\gamma-\mathrm{Fe}_{2} \mathrm{O}_{3}$ NP were dispersed in Teflon before analysis. Volumetric adsorptions of nitrogen at $77 \mathrm{~K}$ and $\mathrm{CO}_{2}$ at $273 \mathrm{~K}$ were performed on a ASAP 2020 Micromeretics apparatus. Before analysis, the samples were degassed overnight at $110^{\circ} \mathrm{C}$ under high vacuum $\left(10^{-6} \mathrm{bar}\right)$. 


\subsection{Photocatalytic activity tests}

The photoactivity of the two catalysts $\left(\gamma-\mathrm{Fe}_{2} \mathrm{O}_{3} \mathrm{NP}\right.$ and $\left.\gamma-\mathrm{Fe}_{2} \mathrm{O}_{3} / \mathrm{SiO}_{2} \mathrm{MS}\right)$ was tested for the degradation of three aqueous pollutants, methylene blue (MB), methyl orange (MO), or paranitrophenol (PNP). The chemical structure of these three compounds can be found in the ESI (fig. S1). All of the experimental investigations were carried out in a cylindrical double jacketed glass reactor ( $4 \mathrm{~cm}$ diameter, $6 \mathrm{~cm}$ height) with $20 \mathrm{~mL}$ of reaction volume in contact with the atmospheric air (see the photograph and scheme of the reactor in fig. S2 of the ESI). The reactor was maintained at a fixed temperature $\left(\mathrm{T}=40^{\circ} \mathrm{C}\right)$, which was controlled by circulating water. This temperature was chosen due to several studies which have reported that the temperature range $35-45^{\circ} \mathrm{C}$ is an optimum to promote the degradation and mineralization of pollutants in Fenton-type processes.[41] Bellow these temperatures, the rate of production of $\mathrm{HO}^{\circ}$ radicals is limited, which decreases the removal efficiency of the catalyst, whereas above these temperatures, it has been found that the catalytic activity can be decreased, due to the increase of decomposition rate of $\mathrm{H}_{2} \mathrm{O}_{2}$ in oxygen and water without producing $\mathrm{HO}^{\circ}$ radicals. We also performed some preliminary Fenton tests on the MS catalyst, using MB as model pollutant. These tests have also shown that the performance of the MS catalyst is lower at $\mathrm{T}=30^{\circ} \mathrm{C}$ than at $\mathrm{T}=40^{\circ} \mathrm{C}$.

The visible irradiation source was an Osram 46W halogen lamp vertically placed in the center of the reactor, and surrounded by the two glass jackets and the circulating water. The visiblelight illuminance in the center of the photoreactor $(75 \pm 3 \mathrm{Klux})$ was measured with a digital TES 1335 light meter. The UV-visible emission spectrum of the halogen lamp was taken using an Ocean Optics S2000 spectrometer (for the spectrum, see fig. S3 in the ESI). The relative spectral irradiance at each wavelength (raw measurements) was converted into absolute spectral irradiance through the use of the Abney equation (see the appendix in the ESI). [42] The integration of the spectrum from $\lambda=200 \mathrm{~nm}$ to $880 \mathrm{~nm}$ enables to estimate the total irradiance (in the UV, visible and NIR part of the spectrum), which is equal to $E_{e}=480$ $\mathrm{W} \mathrm{m}{ }^{-2}$. While a halogen lamp can emit a small amount of UV light, the emission spectrum of the lamp showed that the UV light intensity is negligible in the photoreactor, which can be explained by the natural filter formed by the double glass jackets and the circulating water.

The standard photocatalytic tests were conducted as follows. $0.6 \mathrm{~g}$ of $\gamma-\mathrm{Fe}_{2} \mathrm{O}_{3} / \mathrm{SiO}_{2} \mathrm{MS}$, or $420 \mu \mathrm{L}$ of the $\gamma-\mathrm{Fe}_{2} \mathrm{O}_{3} \mathrm{NP}$ acidic aqueous dispersion (both equivalent to $[\mathrm{Fe}]_{\mathrm{T}}=3.15 \times 10^{-2} \mathrm{~mol}$ $\mathrm{L}^{-1}$ in the final reaction mixture) was added to an aqueous solution of the pollutant, which $\mathrm{pH}$ was previously adjusted at 3 by addition of $\mathrm{HNO}_{3}$. The volume of this solution was chosen in a 
manner that the initial concentration of the pollutant in the final mixture was $C_{i}=2.5 \times 10^{-4}$ $\mathrm{molL}^{-1}$ for a total volume of $20 \mathrm{~mL}$ (except for the MB pollutant with the MS catalyst, where $\mathrm{C}_{\mathrm{i}}$ was fixed at $8 \times 10^{-4} \mathrm{~mol} \mathrm{~L}^{-1}$ to take into account the much larger adsorption of this compound on the silica surface). Before turning on the lamp, the suspension was magnetically stirred for $2 \mathrm{~h}$ to establish the adsorption equilibrium. Then the photocatalytic oxidation was initiated by turning on the halogen lamp and by simultaneously adding $\mathrm{H}_{2} \mathrm{O}_{2}$ (1.36 mL of a $30 \%$, (w/w) commercial aqueous solution, corresponding to an initial concentration of $\mathrm{H}_{2} \mathrm{O}_{2}$ of $0.68 \mathrm{~mol} \mathrm{~L}^{-1}$ ) to the system. The solution samples were taken at desired time intervals, and were put over a magnet to separate the supernatant from the catalysts by magnetic settlement. For the $\gamma-\mathrm{Fe}_{2} \mathrm{O}_{3} \mathrm{NP}$, a concentrated $\mathrm{KCl}$ aqueous solution $\left(50 \mathrm{~g} \mathrm{~L}^{-1}\right)$ was previously added to make aggregation of the nanoparticles and thus to favour their settlement. The supernatant was then recovered and diluted to an adequate concentration before to be analyzed with an UV-visible spectrophotometer (UVIKONXL apparatus). The remaining concentration of the pollutant in the supernatant $\left(\mathrm{C}_{\mathrm{t}}\right)$ was determined using the Beer-Lambert law at 502, 400, and $665 \mathrm{~nm}$ respectively for MO, PNP, and MB. Time zero for reaction take-off was defined as the time when the lamp was turned-on and $\mathrm{H}_{2} \mathrm{O}_{2}$ simultaneously added. The concentration of the pollutant in the supernatant measured at $\mathrm{t}=0$ was noted $\mathrm{C}_{0} \cdot \mathrm{C}_{0}$ varied from $1.8 \times 10^{-4}$ to $2.5 \times 10^{-4} \mathrm{~mol} \mathrm{~L}^{-1}$, depending on the amount of adsorbed pollutant on the catalyst. The initial rate of decolorization $\left(\mathrm{v}_{0}\right)$ was determined by plotting the tangent at $\mathrm{t}=0$ of the kinetic curve $\mathrm{C}_{\mathrm{t}}=\mathrm{f}(\mathrm{t})$. The decolorization yield (DY) at $3 \mathrm{~h}$, was also evaluated from this curve, using the following equation (1).

$$
\mathrm{DY}=100-100 \cdot \mathrm{C}_{3 \mathrm{~h}} / \mathrm{C}_{0}
$$

Where $\mathrm{C}_{3 \mathrm{~h}}$ and $\mathrm{C}_{0}$ are the concentrations of pollutant in the supernatant respectively at $\mathrm{t}=3 \mathrm{~h}$ and $\mathrm{t}=0$. Since most of the pollutant should ultimately break down into inorganic ions and molecules, an important aspect of this study is also to evaluate the mineralization of the system. The mineralization yield of the pollutant at $24 \mathrm{~h}$ (MY) was monitored by analyzing the non-purgeable organic carbon (NPOC) in the supernatant using a Shimadzu TOCASI-5000A apparatus and was calculated using the equation (2).

$$
\mathrm{MY}=100-100 \cdot \mathrm{NPOC}_{24 \mathrm{~h}} / \mathrm{NPOC}_{\mathrm{i}}
$$

Where $\mathrm{NPOC}_{24 \mathrm{~h}}$ is the NPOC concentration (in ppm) in the supernatant at $\mathrm{t}=24 \mathrm{~h}$, and $\mathrm{NPOC}_{\mathrm{i}}$ the initial NPOC concentration (before the adsorption equilibrium).The amount of iron ions leached from the catalysts in the solution was determined by measuring the iron 
concentrations in the supernatant at $4 \mathrm{~h}$ using atomic absorption spectrophotometry. The percentage of leached iron $\left(\mathrm{Fe}_{\mathrm{L}}\right)$ was calculated using the following equation (3).

$$
\mathrm{Fe}_{\mathrm{L}}=100 \cdot[\mathrm{Fe}]_{\mathrm{s}, 4 \mathrm{~h}} /[\mathrm{Fe}]_{\mathrm{T}}
$$

Where $[\mathrm{Fe}]_{\mathrm{s}, 4 \mathrm{~h}}$ is the iron concentration in the supernatant at $4 \mathrm{~h}$,and $[\mathrm{Fe}]_{\mathrm{T}}$ the equivalent iron concentration used in the catalytic test $\left([\mathrm{Fe}]_{\mathrm{T}}=3.15 \times 10^{-2} \mathrm{molL}^{-1}\right)$.

Some control experiments in dark were also carried out to study the performance of the Fenton process on the oxidation of the three pollutants, and to evaluate the effect of visible light on the performance of two catalysts. The catalytic and photocatalytic tests at $\mathrm{pH}=5$ and 8 were performed by replacing the $\mathrm{HNO}_{3}$ solution by pure water and $\mathrm{NaOH}$ solution, respectively. The reusability of the $\gamma-\mathrm{Fe}_{2} \mathrm{O}_{3} / \mathrm{SiO}_{2} \mathrm{MS}$ catalyst for four times was evaluated using MO as model pollutant, in absence and in presence of light. The reuse tests were performed as follow. After each catalytic test (corresponding to 4 hours of reaction), the catalyst was separated from the solution by magnetic settlement, rinsed two times with $10^{-3}$ mol L ${ }^{-1} \mathrm{HNO}_{3}$ aqueous solution and two times with water to remove any possible contaminant from the surface. The solid was finally dried in an oven at $70^{\circ} \mathrm{C}$ overnight before the next use. Some additional tests were carried out to measure the activity of the catalysts on the decomposition rate of $\mathrm{H}_{2} \mathrm{O}_{2}$ in absence of any pollutant. The same experimental conditions were used, except that no pollutant solution was added. The solution samples were taken at desired time intervals, and the catalyst was separated from the supernatant by the same procedure. Then the $\mathrm{H}_{2} \mathrm{O}_{2}$ concentration in the supernatant was determined by the following procedure. $0.8 \mathrm{~mL}$ of the supernatant was transferred in a $10 \mathrm{~mL}$ graduated flask containing a large amount of water and $0.28 \mathrm{~mL}$ of $\mathrm{H}_{2} \mathrm{SO}_{4} 98 \%$ solution. The total volume was completed by adding water, in such way that the dilution factor for $\mathrm{H}_{2} \mathrm{O}_{2}$ was 12.5 , and the concentration of $\mathrm{H}_{2} \mathrm{SO}_{4}$ was $0.5 \mathrm{~mol} \mathrm{~L}^{-1}$. An aliquot of this solution was then quickly titrated by a $0.02 \mathrm{~mol}$ $\mathrm{L}^{-1} \mathrm{KMnO}_{4}$ solution. At the equivalent point, which is detected by the persistence of the pink coloration due to $\mathrm{KMnO}_{4}$, the stoichiometric factor between the amounts of $\mathrm{H}_{2} \mathrm{O}_{2}$ and $\mathrm{KMnO}_{4}$ is 2.5 .

\section{Results and discussion}

\subsection{Characterization of the catalyst}

The characterization of the catalysts has been thoroughly described in our previous paper.[35] The main results of this study are summarized in the following paragraph. The morphology of 
the catalysts was examined by SEM and TEM, as depicted in figure 1 (A and B). Fig.1A shows that the $\gamma-\mathrm{Fe}_{2} \mathrm{O}_{3} \mathrm{NP}$ are polydisperse in size and have a rock-like morphology, which can be approximated as spheres having a mean diameter of $\mathrm{d}=8.9 \mathrm{~nm}$ with a standard deviation of $2.4 \mathrm{~nm}$, as obtained from the digitized TEM image of 170 particles in combination with an image analysis software. SEM image of the $\gamma-\mathrm{Fe}_{2} \mathrm{O}_{3} / \mathrm{SiO}_{2} \mathrm{MS}$ (fig. 1B), shows that the silica microsphere supports are polydisperse in size with a relatively smooth external surface. Their mean diameter determined by counting the size of more than 350 beads is $\mathrm{D}=2.0 \mu \mathrm{m}$ with a standard deviation of $1.7 \mu \mathrm{m}$. The TEM image of a bead (see the inset on fig. 1B) shows a homogeneous and isotropic dispersion of the $\gamma-\mathrm{Fe}_{2} \mathrm{O}_{3} \mathrm{NP}$ in the silica, without evidence for the formation of agglomerates or chains, despite the relative high weight fraction of the $\gamma-\mathrm{Fe}_{2} \mathrm{O}_{3} \mathrm{NP}$ in the microspheres (a value of $\mathrm{w}_{\mathrm{Fe} 2 \mathrm{O} 3}=8.1 \% \mathrm{w} / \mathrm{w}$ is found by atomic absorption spectrophotometry).

Magnetic properties of bare $\gamma-\mathrm{Fe}_{2} \mathrm{O}_{3} \mathrm{NP}$ and $\gamma-\mathrm{Fe}_{2} \mathrm{O}_{3} / \mathrm{SiO}_{2} \mathrm{MS}$ were respectively investigated with a vibrating sample magnetometer (VSM) and SQUID magnetometer. The absence of hysteresis in the magnetization curves shows that the $\gamma-\mathrm{Fe}_{2} \mathrm{O}_{3}$ nanoparticles exhibit typical superparamagnetic behaviour (see the curves of fig.S4-A in the ESI), both in the absence and the presence of the silica support. This proves that the magnetic properties of the nanoparticles were preserved after their encapsulation in the silica microspheres. Both curves show in addition a strong magnetic susceptibility. This strong magnetic susceptibility is spectacularly confirmed by the behaviour of the samples in water, in presence of a magnet (see the photographs in fig.1C and 1D). Both materials are strongly attracted by the magnetic force proportional to the strong magnetic field gradient. However the very high colloidal stability of the NP in water restricts their separation from the water, on the contrary of the MS particles which can be completely separated from the solution in a very short time (less than 3 min). The magnetic saturation values determined from the curves are 62 and $66 \mathrm{emu} \mathrm{g}{ }^{-1}$, respectively for the NP and the MS samples (the magnetic saturations are normalised to $1 \mathrm{~g}$ of maghemite). Both values agree well with the value usually given for $\gamma-\mathrm{Fe}_{2} \mathrm{O}_{3}$ nanoparticles $\left(\mathrm{M}_{\mathrm{s}}=60 \mathrm{emu} \mathrm{g}^{-1}\right)$. [43] The diffraction patterns (see fig. S4-B) obtained for the magnetic nanoparticles before and after their supporting in the silica micropheres are similar, and corresponds well to the spinel structure of maghemite, confirming that the $\gamma-\mathrm{Fe}_{2} \mathrm{O}_{3}$ nanoparticles are not altered by their encapsulation in the silica matrix. The average crystal size of nanoparticles calculated from the XRD pattern using the Scherrer formula is $d=7.1 \mathrm{~nm}$, which agrees well with the diameter of the $\gamma-\mathrm{Fe}_{2} \mathrm{O}_{3} \mathrm{NP}$ obtained by TEM image. The absence 
of variety of iron other than maghemite is also confirmed by the UV-Vis-NIR spectra of the $\gamma$ $\mathrm{Fe}_{2} \mathrm{O}_{3} \mathrm{NP}$ and $\gamma-\mathrm{Fe}_{2} \mathrm{O}_{3} / \mathrm{SiO}_{2} \mathrm{MS}$ catalysts (see fig.S4-C).
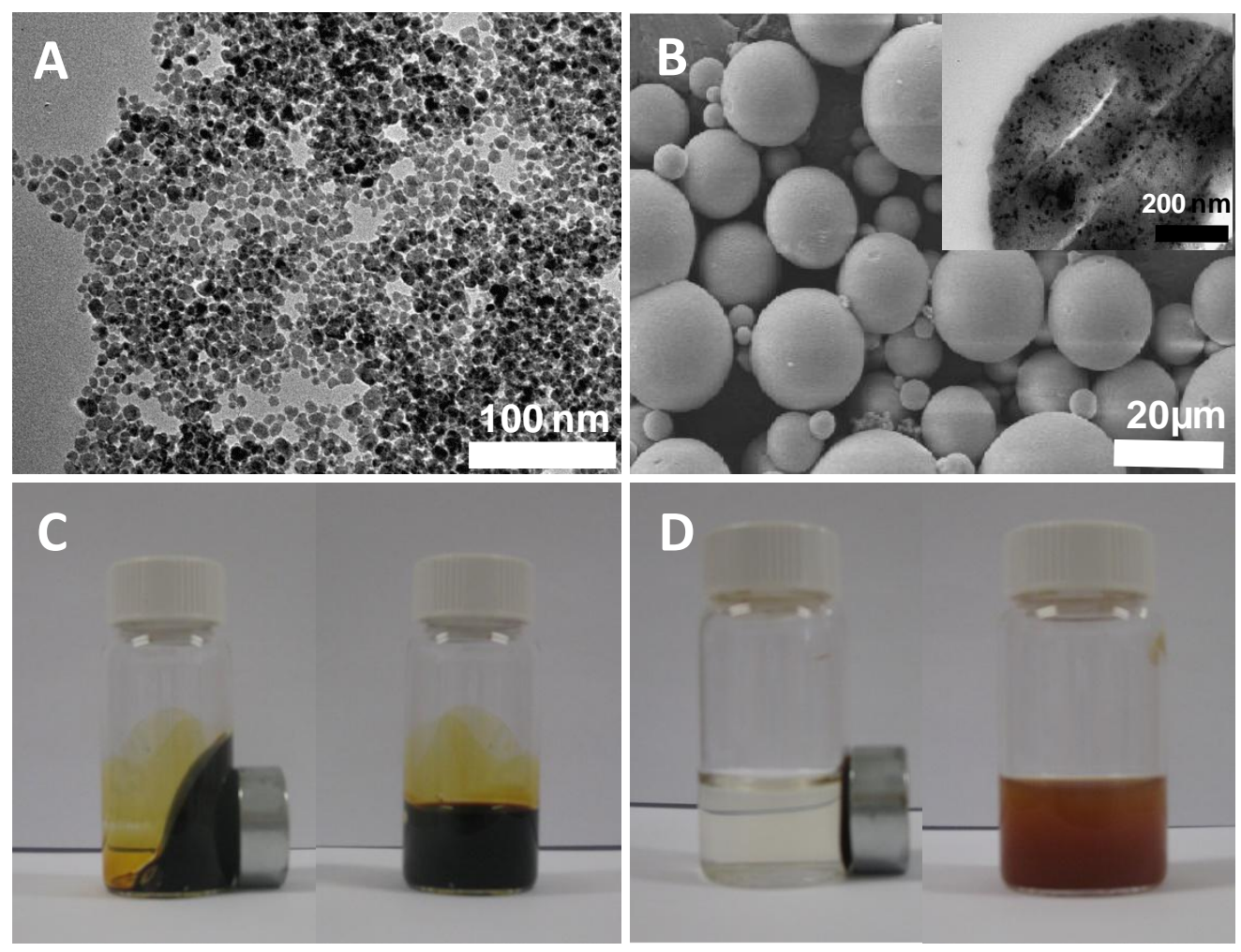

Fig.1: (A) TEM image of the $\gamma-\mathrm{Fe}_{2} \mathrm{O}_{3}$ NP. (B) SEM image of the $\gamma-\mathrm{Fe}_{2} \mathrm{O}_{3} / \mathrm{SiO}_{2} \mathrm{MS}$. In inset: TEM image of a $\gamma-\mathrm{Fe}_{2} \mathrm{O}_{3} / \mathrm{SiO}_{2} \mathrm{MS}$. (C) Photograph of the water dispersion of the $\gamma-\mathrm{Fe}_{2} \mathrm{O}_{3} \mathrm{NP}$ (with/ without magnet). (D) Photograph of the water suspension of the $\gamma-\mathrm{Fe}_{2} \mathrm{O}_{3} / \mathrm{SiO}_{2} \mathrm{MS}$ (with/without magnet).

The porosity of the materials was determined by sorption volumetry of $\mathrm{N}_{2}$ and $\mathrm{CO}_{2}$ (respectively at $77 \mathrm{~K}$ and $273 \mathrm{~K}$ ). Both are characterized by a large surface area, which is of prime importance to obtain some high catalytic activities. For the $\gamma-\mathrm{Fe}_{2} \mathrm{O}_{3} \mathrm{NP}$, the $\mathrm{N}_{2}$ isotherm (see fig. S4-D) is of type II, which is observed for finely divided non-porous solids. By applying the BET equation to the first part of the isotherm, it was found that the specific surface area is $159 \mathrm{~m}^{2} \mathrm{~g}^{-1}$, which corresponds to the theoretical external surface of spherical particles having a mean diameter of $\mathrm{d}=7.4 \mathrm{~nm}$. For the $\gamma-\mathrm{Fe}_{2} \mathrm{O}_{3} / \mathrm{SiO}_{2} \mathrm{MS}$, the $\mathrm{N}_{2}$ isotherm (see fig. S4-D) is of type I, which is characteristic of a microporous solid with pore diameters smaller than $2 \mathrm{~nm}$. The calculus of the BET surface area from the $\mathrm{N}_{2}$ isotherm being inoperative for microporous solids, $\mathrm{CO}_{2}$ adsorption volumetry was practiced on the MS.[35] By modelling this isotherm with the Dubinin-Astakhov equation,[44] a surface area (S) of 744 
$\mathrm{m}^{2} \mathrm{~g}^{-1}$ and a microporous volume $\left(\mathrm{V}_{\mathrm{p}}\right)$ of $0.30 \mathrm{~mL} \mathrm{~g}^{-1}$ were found for the beads. These values confirm the large amount of micropores in the silica network. In addition, the mean diameter of the micropores, $D_{p}$, was calculated using the relation $D_{p}=4 V_{p} / S$.A value of $D_{p}=1.6 \mathrm{~nm}$ was found, showing that the micropores have a relatively large size, which may allow the diffusion of the pollutants into the beads.

\subsection{Photocatalytic tests on the three pollutants}

The performance of the two catalysts, $\gamma-\mathrm{Fe}_{2} \mathrm{O}_{3} \mathrm{NP}$, and $\gamma-\mathrm{Fe}_{2} \mathrm{O}_{3} / \mathrm{SiO}_{2} \mathrm{MS}$, was examined under both dark (heterogeneous Fenton process) and visible light (heterogeneous photoFenton process) conditions. Their activity on the oxidation by $\mathrm{H}_{2} \mathrm{O}_{2}$ of the three aqueous pollutants (MO, MB, and $\mathrm{PNP}$ ) was first tested at $\mathrm{pH}=3$ and $\mathrm{T}=40^{\circ} \mathrm{C} . \mathrm{H}_{2} \mathrm{O}_{2}$ was added $2 \mathrm{~h}$ after the adsorption of the pollutant on the catalyst $(t=0)$. The decolorization and the mineralization kinetics of the solutions were respectively followed by UV-visible spectroscopy, and measurement of the NPOC. The iron leaching of the catalysts was measured by analysis of the iron concentration in the supernatants after $4 \mathrm{~h}$, using atomic absorption spectroscopy. In addition, to estimate the activity of the catalysts independently of the nature of the pollutant, the decomposition rate of $\mathrm{H}_{2} \mathrm{O}_{2}$ was determined by measurement of the $\mathrm{H}_{2} \mathrm{O}_{2}$ concentration at fixed times, using $\mathrm{KMnO}_{4}$ titration, in absence of the pollutants. Figure 2 shows the kinetic curves obtained for the MO decolorization (fig.2A), the MO mineralization (fig.2B), and the $\mathrm{H}_{2} \mathrm{O}_{2}$ decomposition (fig. 2C) in the supernatant. Other kinetic curves (MB and PNP decolorization and mineralization) and the resulting data can be found in the ESI (fig. S5 and table S1). 

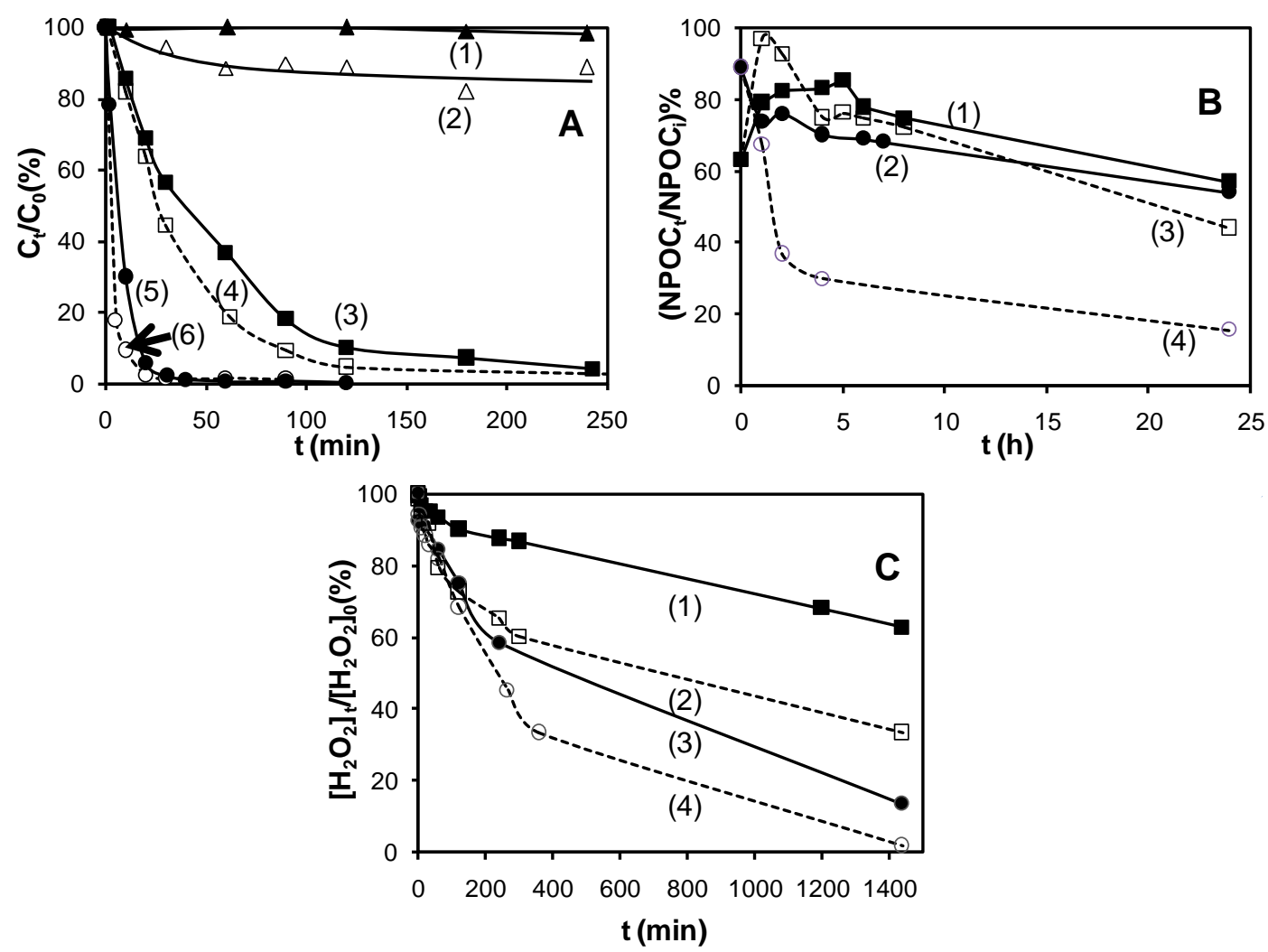

Fig.2 : (A) Kinetic curves for the decolorization of the MO solutions (The MO concentration, $\mathrm{C}_{\mathrm{t}}$ is normalized to $\mathrm{C}_{0}$, the MO concentration at $\left.\mathrm{t}=0\right):(1)=$ without catalyst, absence of light,

(2) = without catalyst, presence of the visible light, (3) = MS catalyst, Fenton, (4) = MS catalyst, photo-Fenton, (5) = NP catalyst, Fenton, (6) = NP catalyst, photo-Fenton.(B) Kinetic curves for the mineralization of the MO solutions(The NPOC concentration, $\mathrm{NPOC}_{\mathrm{t}}$ is normalized to $\mathrm{NPOC}_{\mathrm{i}}$, the initial NPOC concentration, before adsorption equilibrium) (1) MS catalyst, Fenton, (2) NP catalyst, Fenton, (3) MS catalyst, photo-Fenton, (4) NP catalyst, photo-Fenton.(C) Kinetic curves for the $\mathrm{H}_{2} \mathrm{O}_{2}$ decomposition (The $\mathrm{H}_{2} \mathrm{O}_{2}$ concentration, $\left[\mathrm{H}_{2} \mathrm{O}_{2}\right]_{t}$ is normalized to $\left[\mathrm{H}_{2} \mathrm{O}_{2}\right]_{0}$, the $\mathrm{H}_{2} \mathrm{O}_{2}$ concentration at $\left.\mathrm{t}=0\right):(1)=\mathrm{MS}$ catalyst, Fenton, $(2)=\mathrm{MS}$ catalyst, photo-Fenton, (3) = NP catalyst, Fenton , (4) = NP catalyst, photo-Fenton.

In absence of catalyst, the $\mathrm{MO}$ solutions remain almost stable under the addition of $\mathrm{H}_{2} \mathrm{O}_{2}$ even in presence of illumination by visible light (see curves (1) and (2), fig. 2A). To the contrary, the addition of the MS or NP catalyst allows nearly total decolorizations of the MO solutions after few hours (see curves (3) to (6), fig.2A), and significant mineralization yields after $24 \mathrm{~h}$ (see fig.2B), which is related to important decomposition rates of $\mathrm{H}_{2} \mathrm{O}_{2}$ (see fig.2C). To explain the correlation between the $\mathrm{MO}$ oxidation (fig.2A and 2B) and the $\mathrm{H}_{2} \mathrm{O}_{2}$ 
decomposition (fig. 2C) we have to take into account that a faster $\mathrm{H}_{2} \mathrm{O}_{2}$ decomposition leads to a larger production of $\mathrm{HO}^{\circ}$ radicals which are responsible for the $\mathrm{MO}$ oxidation. The mineralization of the MO solutions (fig. 2B) occurs much more slowly than their decolorization (fig.2A), as already mentioned by other authors.[16,45] The best mineralization yields (55.9\% for the MS catalyst and $84.5 \%$ for the NP catalyst) are obtained at $24 \mathrm{~h}$ for the photo-Fenton process, clearly showing the interest of using a visible lamp. The patterns of the mineralization curves are rather complex. At $\mathrm{t}=0$, the NPOC values are smaller than expected, because of the adsorption of a small part of the pollutant on the NP or MS catalysts. During the first hours of the reaction, the amount of NPOC is increased, especially for the MS catalyst, which can be interpreted in terms of desorption of the primary organic species resulting from the early degradation of the adsorbed MO. Finally, the NPOC is gradually decreased up to $24 \mathrm{~h}$, which is due to the slow mineralization of these primary organic species. However, the same trends are observed by the three measurements (decolorization, mineralization, and $\mathrm{H}_{2} \mathrm{O}_{2}$ decomposition). First, the NP catalyst is more efficient than the MS catalyst, in presence or in absence of light. The lower activity of the MS catalyst can be explained by the difficulty for the reactants to access to the surface of the $\gamma$ $\mathrm{Fe}_{2} \mathrm{O}_{3} \mathrm{NP}$, encapsulated in the core of the silica microspheres. Second, the efficiency of the two catalysts is greatly improved by irradiating the suspensions with visible light. This positive influence of the visible irradiation is due to an increase of the production of the $\mathrm{HO}^{*}$ radicals at the surface of the catalyst, as already observed by several authors for similar processes.[18,22,25,26] Interestingly, this increase occurs without additional Fe leaching, which remains less than $0.4 \%$ (see table S1 in the ESI part).These results can be generalized to the two other pollutants, MB and PNP. Figure 3 shows the initial decolorization rates $\left(\mathrm{v}_{0}\right.$, fig. 3A) and the mineralization yields at 24h (MY, fig. 3B) obtained for the three pollutants with the two catalysts, in the absence and in the presence of visible light. 

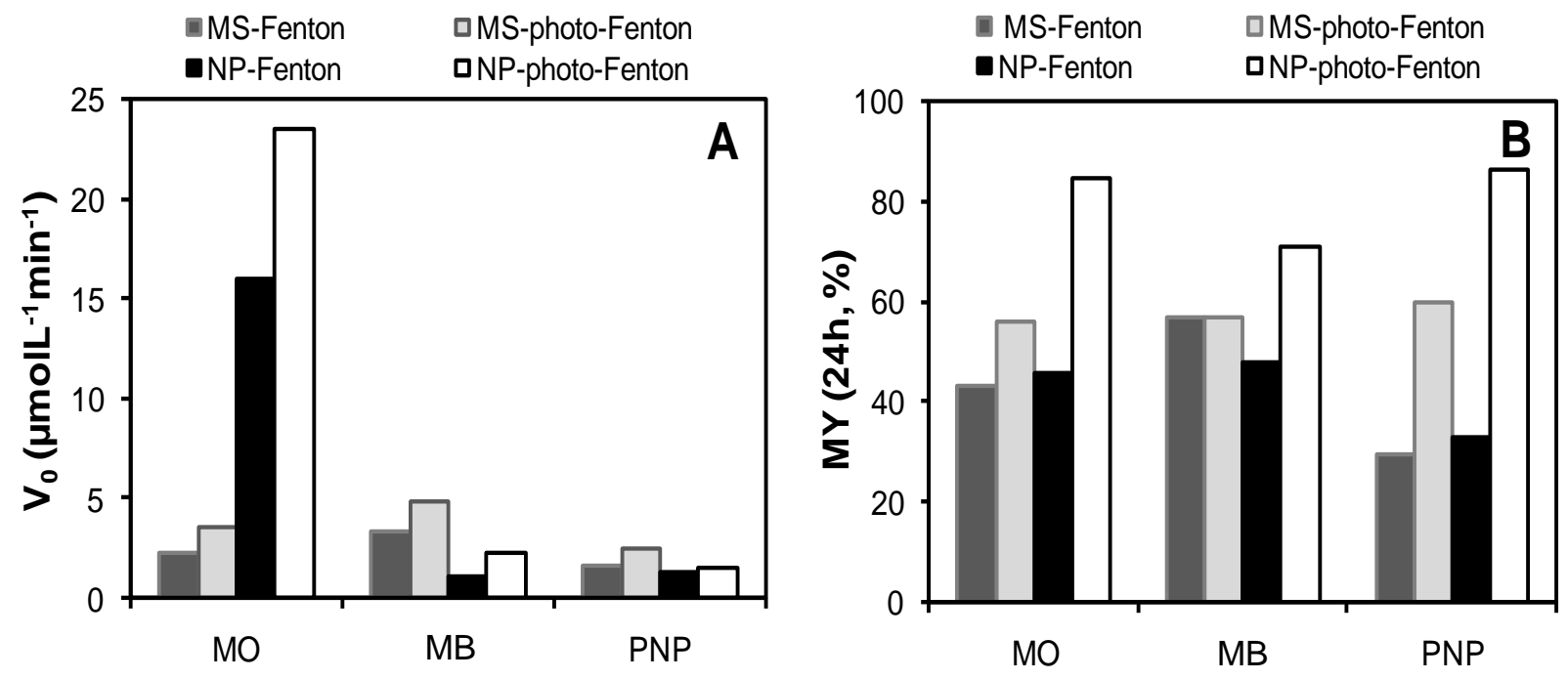

Fig.3 : (A) Initial decolorization rates $\left(\mathrm{v}_{0}\right)$ for the three pollutants (MO, $\mathrm{MB}$, and PNP). (B)

Mineralization yields (MY) at $24 \mathrm{~h}$ for the three pollutants (MO, MB, and PNP).

The decolorization and mineralization rates strongly vary with the pollutant, and it is difficult to highlight a clear trend, which depends on the catalyst, the process, and what it is measured (decolorization or mineralization). The NP catalyst is generally more efficient than the MS catalyst, but the results for PNP and MB are not as straight forward as for MO or for $\mathrm{H}_{2} \mathrm{O}_{2}$ decomposition, especially regarding decolorization. In some cases, comparable or even larger rates can be obtained with the MS catalyst, despite the fact that the accessibility of the reactants to the catalytic sites is lowered by the presence of the silica. This demonstrates that the decolorization rate is influenced by other parameters, such as the adsorption level of the pollutant, its stability to the attack of the $\mathrm{HO}^{\bullet}$ radicals, and the existence of several colorized degradation intermediates at the first stages of the process. In a recent paper, it has been shown in particular that the reactivity of a pollutant toward an AOP can dramatically change, depending on the electrostatic interactions between the pollutant and the support. [46] The oxidation is generally favored when the charges are opposite. This can explain why in our case the decolorization of $\mathrm{MB}$, a positively charged molecule, is increased in presence of silica, a negatively charged support. Nevertheless, all the data clearly show that the Fentonlike oxidation of the pollutants is considerably improved through the use of the visible lamp, although the importance of this improvement vary with the pollutant, the catalyst and the measured parameter. Concerning the decolorization rates (fig. $3 \mathrm{~A}$ ), $\mathrm{v}_{0}$ is about 1.2 to 2.1 times faster for the NP catalyst, and 1.5 to 1.6 times faster for the MS catalyst when visible lamp is 
used. These higher rates lead to quasi-quantitative decolorization yields in only $3 \mathrm{~h}$, while it takes at least $4 \mathrm{~h}$ for the reaction in the dark (see table S1). It is important to note that the level of $\mathrm{v}_{0}$ increase due to visible light (fig. 3A) is comparable to the level of increase in $\mathrm{H}_{2} \mathrm{O}_{2}$ degradation rate (fig. 2C), which is of same order of magnitude (around 1.5 to 2). Therefore, during the early stages of the degradation, which corresponds to the decolorization, the efficiency of irradiation seems to be poorly influenced by the presence of the pollutant.

For mineralization (fig. 3B), best results are obtained for the NP catalyst, with very good mineralization yields under visible light ( $\mathrm{MY}=70.8 \%$ to $86.3 \%)$. For the MS catalyst, we also noted somewhat good mineralization yields in the same conditions (MY=57.0\% to 59.8\%). The lower MY values obtained for the two catalysts in the absence of light (MY=29.3\% to $56.9 \%$ ) indicate that the dark Fenton process is not effective for the mineralization of the pollutants, a major limitation of this process, as also observed in relevant studies. [47,48]

Thus, the level of mineralization is generally well correlated to the decolorization rate : a high initial $\mathrm{v}_{0}$ generally leads to a MY at $24 \mathrm{H} 00$. However there is no simple relationship between the initial decolorization rate and the amount of mineralized pollutant, and sometimes a relatively moderate $\mathrm{v}_{0}$ leads to relatively good MY at $24 \mathrm{H} 00$, as it is observed for example in the case of MB. This is explained by the great difference between the processes respectively measured by decolorization and mineralization. When measuring the decolorization, we measure in fact the result of few competitive reactions between the $\mathrm{HO}^{\circ}$ radicals and the model pollutant (MO, MB or PNP), occurring during the few first hours and leading to uncolored intermediates having a chemical structure relatively close to the parent molecule. To the contrary, mineralization is the result of numerous competitive and consecutives oxidative reactions occurring during 24 hours, which lead finally to $\mathrm{CO}_{2}, \mathrm{H}_{2} \mathrm{O}$ and inorganic salts. The kinetic of this complex process depends on the reactivity of all the formed intermediates towards the $\mathrm{HO}^{\circ}$ radicals (and also towards other radical species such as $\mathrm{HO}_{2}{ }^{\circ}$ or $\mathrm{O}_{2}{ }^{-}$). The nature of these intermediates depends on the nature of the parent molecule but also on the presence or absence of light, and on the nature of the catalyst. Therefore, in some cases, the uncolored intermediates can be formed relatively slowly due to the relative stability of the parent molecule towards oxidation, which lead to moderate $v_{0}$, but they may react relatively fast with the $\mathrm{HO}^{\circ}$ radicals, which leads to relatively high values of MY after $24 \mathrm{HOO}$.

It should also be noted that the best MY gains due to visible light are always obtained with the NP catalysts, showing a better efficiency of the illumination for this catalyst. The reduced 
efficiency of visible light with the MS catalyst may be caused by the larger turbidity of the solution, due to the large size of the $\gamma-\mathrm{Fe}_{2} \mathrm{O}_{3} / \mathrm{SiO}_{2}$ particles, which may slightly decrease the penetration of visible light into the reactor. This is contradictory to what has been observed for decolorization, probably because this effect is appreciable only at long term, after several hours of illumination. Concerning the influence of the pollutant on the irradiation efficiency, larger gains are generally obtained for PNP, where mineralization yields are increased by a factor 2 to 2.5.To the contrary, the gain obtained for MB with the MS catalyst is negligible. These differences cannot be explained by the lower light absorption of PNP $\left(\varepsilon L=9531 \mathrm{~L} \mathrm{~mol}^{-1}\right.$ at $\left.\lambda_{\max }=317 \mathrm{~nm}\right)$ in comparison to MO or MB $\left(\varepsilon L=34500 \mathrm{~L} \mathrm{~mol}^{-1}\right.$ and $79600 \mathrm{~L} \mathrm{~mol}^{-1}$ at $\lambda_{\max }=$ $502 \mathrm{~nm}$ and $665 \mathrm{~nm}$, respectively), since mineralization mainly occurs later after decolorization. Here again, the explanation could be in the different mineralization pathways of the pollutants, which may vary in the presence of light. The difference could be especially due to the changes in the concentration of compounds recalcitrant to mineralization, such as oxalic, formic or acetic acid which have been identified as major end-products during Fenton and photo-Fenton processes. $[49,50]$

From these results, a discussion can be made about the mechanism of the catalytic activity under visible light. Several studies have demonstrated that the higher efficiency of photoFenton process is due to the formation of more $\mathrm{HO}^{\circ}$ radicals than in the dark Fenton process. In absence of light, the production of $\mathrm{HO}^{\circ}$ is mainly due to the following reaction $\left(\mathrm{k}_{\mathrm{obs}}=76 \mathrm{~L}\right.$ $\mathrm{mol}^{-1} \mathrm{~s}^{-1}$ in homogenous phase). [51, 52]

$$
\mathrm{Fe}^{2+}+\mathrm{H}_{2} \mathrm{O}_{2} \rightarrow \mathrm{Fe}^{3+}+\mathrm{HO}^{-}+\mathrm{HO}^{\bullet}
$$

The catalytic cycle is completed by the following reaction:

$$
\mathrm{Fe}^{3+}+\mathrm{H}_{2} \mathrm{O}_{2} \rightarrow \mathrm{Fe}^{2+}+\mathrm{HO}_{2}^{\cdot}+\mathrm{H}^{+}
$$

But this last step is relatively slow $\left(\mathrm{k}_{\mathrm{obs}}=0.01 \mathrm{~L} \mathrm{~mol}^{-1} \mathrm{~s}^{-1}\right.$, in homogenous phase $)$ which decreases the efficiency of the iron based catalysts in the dark. In the presence of light, three pathways have been proposed to explain the increase of the catalytic activity. The first mechanism (reactions (3)-(4)) is due to the photo-reduction of $\mathrm{Fe}(\mathrm{III})$ to $\mathrm{Fe}$ (II) which accelerates the regeneration of $\mathrm{Fe}^{2+}$ ions, and at the same time produces additional $\mathrm{HO}^{\circ}$ radicals.[53]

$$
\mathrm{Fe}^{3+}+\mathrm{H}_{2} \mathrm{O} \rightarrow \mathrm{Fe}(\mathrm{OH})^{2+}+\mathrm{H}^{+}
$$




$$
\mathrm{Fe}(\mathrm{OH})^{2+}+\mathrm{h} \nu \rightarrow \mathrm{Fe}^{2+}+\mathrm{HO}^{\bullet}
$$

Since in homogenous phase, the $\mathrm{Fe}(\mathrm{OH})^{2+}$ mainly absorbs in the UV region, the second step (reaction (4)) is operative under UV irradiation $(\lambda \approx 310 \mathrm{~nm})$.

In the second pathway (reactions (5)-(6)), called "dye-sensitization", a colored molecule (a dye) can absorb visible light energy, thus being activated to an excited state. Then the excited dye molecule can transfer an electron to $\mathrm{Fe}(\mathrm{III})$ to generate $\mathrm{Fe}(\mathrm{II})$, which can promote the $\mathrm{Fe}(\mathrm{III}) / \mathrm{Fe}(\mathrm{II})$ catalytic cycle.[54,55]

$$
\begin{aligned}
& \text { Dye }+ \text { visible light } \rightarrow \text { Dye }^{*} \\
& \text { Dye }^{*}+\mathrm{Fe}^{3+} \rightarrow \mathrm{Fe}^{2+}+\mathrm{Dye}^{+\bullet}
\end{aligned}
$$

The third pathway (reactions (7)-(9)) is based on the semiconducting properties of iron oxides. When the band gap of $\mathrm{Fe}_{2} \mathrm{O}_{3}$ is illuminated by $\mathrm{UV}$ or visible light, electron-hole pairs are generated. Then the electrons present in the conduction band can be trapped by the surface $\mathrm{Fe}^{3+}$ leading to $\mathrm{Fe}^{2+}$, or can react with $\mathrm{H}_{2} \mathrm{O}_{2}$ forming $\mathrm{HO}^{\bullet}$ radicals. [12, 48]

$$
\begin{aligned}
& \mathrm{Fe}_{2} \mathrm{O}_{3}+\mathrm{h} v \rightarrow \mathrm{Fe}_{2} \mathrm{O}_{3}\left(\mathrm{e}_{\mathrm{CB}}^{-}, \mathrm{h}^{+}{ }_{\mathrm{VB}}\right) \\
& \mathrm{e}_{\mathrm{CB}}^{-}+\mathrm{Fe}^{3+} \rightarrow \mathrm{Fe}^{2+} \\
& \mathrm{e}_{\mathrm{CB}}^{-}+\mathrm{H}_{2} \mathrm{O}_{2}+\mathrm{H}^{+} \rightarrow \mathrm{H}_{2} \mathrm{O}+\mathrm{HO}
\end{aligned}
$$

The first proposed mechanism is inoperative to explain our results, since photoreduction of the $\mathrm{Fe}^{3+}$ ions only occurs under UV light. The dye-sensitization mechanism is not predominant, at least in the beginning of the oxidative process. Indeed, during the early stages of the degradation of the pollutant - which are detected by the measurement of the decolorization - it seems that the increase of the catalytic activity induced by visible light is poorly influenced by the presence of the pollutant. In other words, the absorption of a part of the visible light by the pollutant has no impact on the photocatalytic activity. To the contrary, the fact that in the absence of any pollutant, visible light has a similar impact on the rate of $\mathrm{H}_{2} \mathrm{O}_{2}$ degradation stands for a mechanism principally based on photogenerated electron-hole pairs (reactions (7)-(9)). To explain that reaction (7) can be promoted by visible light, it has to be considered that the band gap of $\gamma-\mathrm{Fe}_{2} \mathrm{O}_{3}$ is sufficiently low $\left(E_{g}=2.2 \mathrm{eV}\right)$ to be sensitive to visible light. Thus, our results are in good agreement with a predominant mechanism based on photogenerated electron-hole pairs, although a more complex pathway associating photogenerated electron-hole pairs and dye-sensitization may be suggested to explain the 
effect of visible light, and especially the differences in the mineralization yields which result from the late stages of the degradation process.

\subsection{Influence of experimental parameters}

Further studies were carried out to evaluate the effect of different reaction variables, especially the solution $\mathrm{pH}$, the hydrogen peroxide concentration, the amount of catalyst and the light intensity of the lamp. We examined the influence of these parameters on the decolorization kinetics, using MO as model pollutant. The results concerning the influence of the $\mathrm{pH}, \mathrm{H}_{2} \mathrm{O}_{2}$ concentration, and amount of catalyst on $\mathrm{v}_{0}$ are given in figure 4 . The results concerning the influence of light intensity can be found in ESI (figure S6).
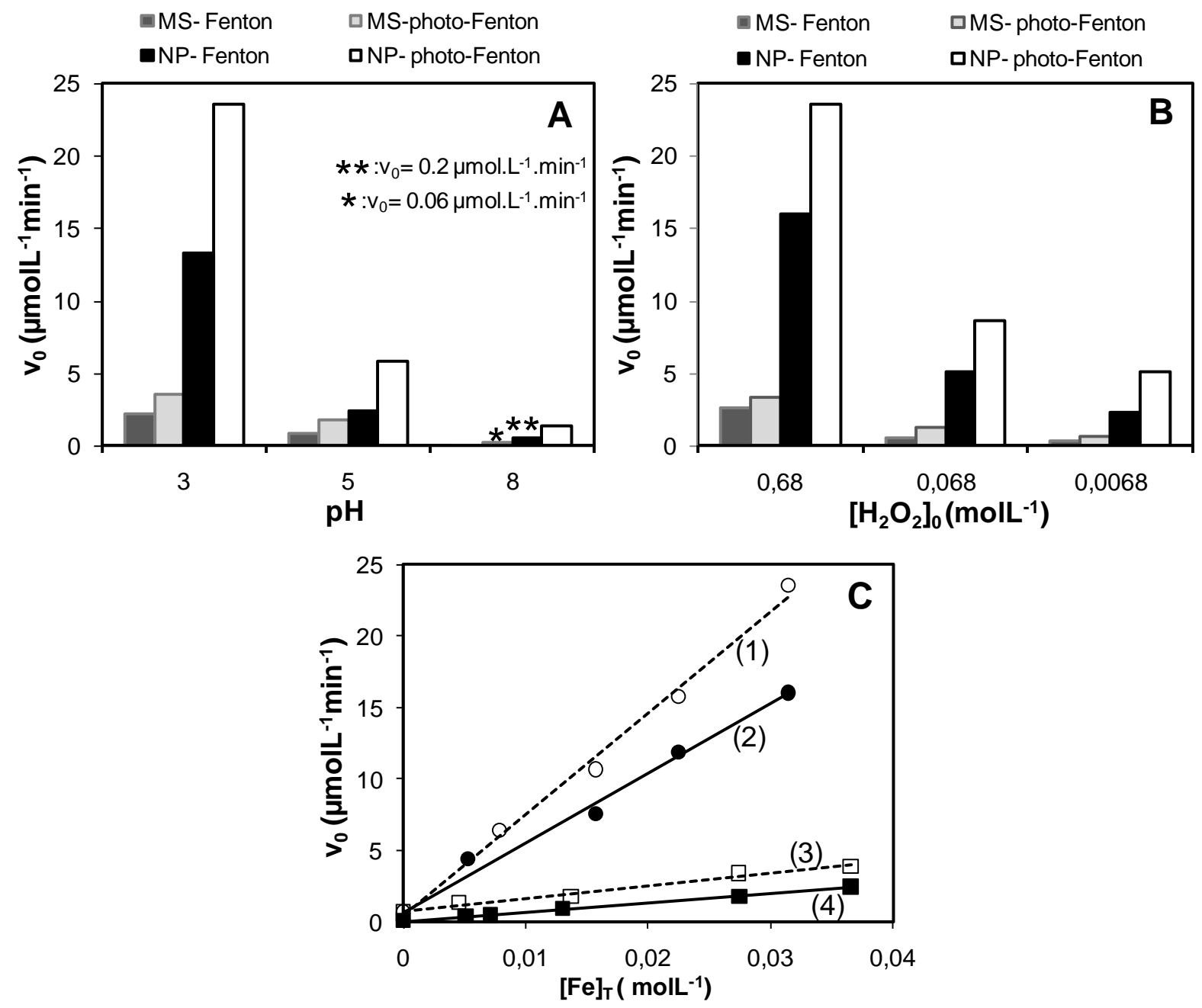

Fig.4: Influence of various parameters on the initial decolorization rate $\left(\mathrm{v}_{0}\right)$, using $\mathrm{MO}$ as model pollutant. (A) pH. (B) Initial concentration of $\mathrm{H}_{2} \mathrm{O}_{2}\left(\left[\mathrm{H}_{2} \mathrm{O}_{2}\right]_{0}\right)$. (C) Amount of catalyst $\left([\mathrm{Fe}]_{\mathrm{T}}\right)$ : (1) NP-photo-Fenton, (2) NP-Fenton, (3) MS-photo-Fenton,(4) MS-Fenton. 


\subsubsection{Effect of the $\mathrm{pH}$}

The $\mathrm{pH}$ is an important parameter to study, since the Fenton and photo-Fenton reactions are strongly $\mathrm{pH}$ dependent. It has been mentioned in the literature that the generation of the $\mathrm{HO}^{\circ}$ radicals, and thus the efficiency of the oxidation is optimum at acidic $\mathrm{pH}$ and decreases as the pH increases. [20] The decrease of the catalytic activity in homogeneous phase when the $\mathrm{pH}$ is increased, is also explained by the precipitation of the soluble the $\mathrm{Fe}^{2+}$ and $\mathrm{Fe}^{3+}$ ions as poorly active iron (II) and (III) hydroxides. Therefore, the application of homogeneous Fenton catalysts is generally limited to a narrow $\mathrm{pH}$ range (around $\mathrm{pH}=3$ ), and the heterogenization of this process is of prime importance to obtain a catalyst capable of maintaining its efficiency in a large $\mathrm{pH}$ range. Our results concerning the effect of the $\mathrm{pH}$ are shown in fig. 4A. This figure shows that the $\mathrm{pH}$ significantly influences the degradation of MO. It can be seen that the increase of the $\mathrm{pH}$ from 3 to 8 leads to a strong decrease of the decolorization rate, independently of the catalyst (MS or NP) or the presence of light. This result is in agreement with other works carried out on iron oxide based heterogeneous Fenton catalysts.[16,18,25,26,48] The highest decolorization rate is obtained at $\mathrm{pH}=3$. When increasing the $\mathrm{pH}$ to 5 (near neutrality), the catalysts are still active but $\mathrm{v}_{0}$ is lowered. Interestingly, the decrease of $\mathrm{v}_{0}$ is smaller in the presence of light (50 and $75 \%$ for MS and NP respectively), than in the dark (59 and $85 \%$ for MS and NP respectively), and the MS catalyst exhibits a smaller loss of activity than the NP catalyst. For all the tests at $\mathrm{pH}=8, \mathrm{v}_{0}$ is reduced from more than 94\%, indicating an important loss of activity. However, in all the range of $\mathrm{pH}$, the best results are obtained under visible light. It is also important to note that the gains due to visible light seems to increase with the $\mathrm{pH}, \mathrm{v}_{0}$ being increased by factors of 1.5-1.6, 2-2.5, and 2.5-3, respectively at $\mathrm{pH}=3,5$ and 8 . The existence of a relatively good catalytic activity at $\mathrm{pH}=5$, may allow these catalysts to be used at neutral $\mathrm{pH}$. These results suggest that $\gamma-\mathrm{Fe}_{2} \mathrm{O}_{3} \mathrm{NP}$ and $\gamma-\mathrm{Fe}_{2} \mathrm{O}_{3} / \mathrm{SiO}_{2} \mathrm{MS}$ used as heterogeneous photo-Fenton catalyst have the potential to overcome the drawback of a narrow $\mathrm{pH}$ range of the conventional Fenton reaction.

\subsubsection{Effect of the $\mathrm{H}_{2} \mathrm{O}_{2}$ dosage}

The dependence of the decolorization efficiency of MO on the initial concentration of $\mathrm{H}_{2} \mathrm{O}_{2}$ $\left(\left[\mathrm{H}_{2} \mathrm{O}_{2}\right]_{0}\right)$, was tested by changing $\left[\mathrm{H}_{2} \mathrm{O}_{2}\right]_{0}$ from $6.8 \times 10^{-3} \mathrm{~mol} \mathrm{~L}^{-1}$ to $0.68 \mathrm{~mol} \mathrm{~L}^{-1}$. The 
relationship between $\mathrm{v}_{0}$ and $\left[\mathrm{H}_{2} \mathrm{O}_{2}\right]_{0}$ is shown in fig. 4B. In all cases, $\mathrm{v}_{0}$ increases with $\left[\mathrm{H}_{2} \mathrm{O}_{2}\right]_{0}$, and the factors of increase are always of the same order $\left(\mathrm{v}_{0}\right.$ is multiplied by 1.7 to 2.2, from $\left[\mathrm{H}_{2} \mathrm{O}_{2}\right]_{0}=6.8 \times 10^{-3} \mathrm{~mol} \mathrm{~L}$ to $6.8 \times 10^{-2} \mathrm{~mol} \mathrm{~L}^{-1}$, and by 2.7 to 4 , from $\left[\mathrm{H}_{2} \mathrm{O}_{2}\right]_{0}=$ $6.8 \times 10^{-2} \mathrm{~mol} \mathrm{~L}^{-1}$ to $0.68 \mathrm{~mol} \mathrm{~L}^{-1}$ ). This trend may be explained by the fact that the increase of $\left[\mathrm{H}_{2} \mathrm{O}_{2}\right]_{0}$ leads to an increase in the amount of $\mathrm{HO}^{\circ}$ radicals, resulting in enhanced efficiencies for the removal of MO. The inhibition steps, such as reactions (10) and (11), which have been observed at high concentration of $\mathrm{H}_{2} \mathrm{O}_{2},[16,18]$ are not predominant in our case, although they may probably exist at a small extent.

$$
\begin{aligned}
& \mathrm{H}_{2} \mathrm{O}_{2}+\mathrm{HO}^{\bullet} \rightarrow \mathrm{H}_{2} \mathrm{O}+\mathrm{HO}_{2}{ }^{\circ} \\
& \mathrm{HO}_{2}{ }^{\bullet}+\mathrm{HO}^{\bullet} \rightarrow \mathrm{H}_{2} \mathrm{O}+\mathrm{O}_{2}
\end{aligned}
$$

Furthermore, the results prove that for both catalysts $\mathrm{v}_{0}$ is always improved with visible light, independently of the initial amount of $\mathrm{H}_{2} \mathrm{O}_{2}$, with slightly larger gains due to visible light for the low values of $\left[\mathrm{H}_{2} \mathrm{O}_{2}\right]_{0}$ ( $\mathrm{v}_{0}$ is increased by factor of 2.2-2.3, and 1.5-1.6, respectively at $\left[\mathrm{H}_{2} \mathrm{O}_{2}\right]_{0}=6.8 \times 10^{-3}$ and $\left.0.68 \mathrm{~mol} \mathrm{~L}^{-1}\right)$. The lowest efficiency of visible light at high concentration of $\mathrm{H}_{2} \mathrm{O}_{2}$ may be correlated to a greater extent of the inhibitory steps (such as reactions (10) and (11)) under illumination. The most important point to retain is that both catalysts are still active at low $\mathrm{H}_{2} \mathrm{O}_{2}$ concentrations, especially under visible light, which has a great potential for an application in water-treatment, where a moderate amount of $\mathrm{H}_{2} \mathrm{O}_{2}$ is required for economical and technical reasons.

\subsubsection{Effect of the amount of catalyst}

The catalyst loading is one of the main parameters that can substantially affect the Fenton and photo-Fenton processes. Usually, it is expected that higher catalyst loadings lead to more rapid degradation of organic compounds. This can be explained by the fact that the rate of $\mathrm{H}_{2} \mathrm{O}_{2}$ decomposition increases with the amount of catalyst, which leads to a larger concentration of $\mathrm{HO}^{\bullet}$ radicals. In this study, the effect of the amount of catalysts was investigated by varying the equivalent concentration of iron from 0 to $3.65 \times 10^{-2} \mathrm{~mol} \mathrm{~L}^{-1}$. The results for Fenton and photo-Fenton processes are shown in fig. 4C. It can be seen that in all the situations, $v_{0}$ linearly increases with the amount of iron. Whatever the amount of catalyst, better activities are obtained under irradiation. At high amount of catalyst, the ratio between $\mathrm{v}_{0}$ under visible light and $\mathrm{v}_{0}$ in the dark is quasi-independent of the amount of catalyst (the ratios vary between 1.5 and 2 for both catalysts). However, for the low amounts of catalyst, 
larger ratios are obtained, especially with the MS catalyst. The better efficiency of visible light at low amount of catalyst can be analyzed in term of the relative importance of the uncatalyzed reaction under illumination. Indeed, assuming an order 1 with respect to the equivalent iron concentration, $\mathrm{v}_{0}$ can be written as:

$$
\mathrm{v}_{0}=\mathrm{k}_{\mathrm{obs}}[\mathrm{Fe}]_{\mathrm{T}}+\mathrm{v}_{0, \text { uncat }}
$$

Where $\mathrm{k}_{\mathrm{obs}}$ is the apparent constant of the catalyzed reaction (the slopes in fig. $4 \mathrm{C}$ ), $[\mathrm{Fe}]_{\mathrm{T}}$ the equivalent iron concentration, and $\mathrm{v}_{0 \text {,uncat }}$ the uncatalyzed initial rate (the ordinates in fig. $4 \mathrm{C}$ ).

The uncatalyzed reaction under visible light is not completely negligible, $\mathrm{v}_{0}$ under visible light being twenty times larger than $\mathrm{v}_{0}$ in the dark (see fig.2A and table S1). For the low values of $[\mathrm{Fe}]_{\mathrm{T}}, \mathrm{v}_{0}$ is relatively small (especially for MS, the less active catalyst), and therefore, when visible light is applied, the contribution of $\mathrm{v}_{0 \text {,uncat }}$ is important, which mathematically increases the value of $\mathrm{v}_{0}$ under light, in comparison to $\mathrm{v}_{0}$ in the dark. Nevertheless, another explanation can be given for the larger efficiency of visible light at low amount of catalyst: the lower turbidity of the solution may enhance the transmission of visible light. However, we would expect to find in that case an absence of linearity between $\mathrm{v}_{0}$ and the amount of catalyst. Finally, the most interesting feature is that the catalysts, when illuminated by visible light, maintain a good activity at very low amount of iron: despite the relative weakness of $\mathrm{v}_{0}$, complete decolorizations can be obtained in few hours for both catalysts, down to a value of $[\mathrm{Fe}]_{\mathrm{T}}=5 \times 10^{-3} \mathrm{molL}^{-1}$, which corresponds to a $\mathrm{H}_{2} \mathrm{O}_{2} / \mathrm{Fe}$ molar ratio of only $200 / 1$.

\subsubsection{Effect of the light intensity}

We tested different commercial halogen lamps differing only in their nominal power which varied from $20 \mathrm{~W}$ to $77 \mathrm{~W}$, on the photo-Fenton degradation of MO in presence of the NP catalyst. These halogen lamps essentially emits in the visible part of the spectrum (The temperature of the filament being at $2700 \mathrm{~K}$ for all the lamps, similar emission spectra can be obtained), and it is well known that the visible light intensity linearly increases with its nominal power.

The experimental results presented in figure S6 clearly show that the rate of $\mathrm{MO}$ decomposition increases with the luminous intensity of the halogen visible lamp. Therefore when the intensity of the light is increased, both the initial rate $\mathrm{v}_{0}$, and the decolorization at 20 
min, are improved. Although the increasing in efficiency seems to be slightly diminished for the larger nominal powers, best results are obtained with the $77 \mathrm{~W}$ lamp, which corresponds to the stronger visible light intensity used in this study (a nominal power of $77 \mathrm{~W}$ is equivalent to a visible light intensity of 1320 lumen according to the manufacturer). This demonstrates the possibility to increase the efficiency of the catalysts by increasing the light intensity of the lamp (the lamp used in our work being usually of $46 \mathrm{~W}$, which is equivalent to a visible light intensity of 700 lumen according to the manufacturer). The increase of the efficiency of the NP with the visible light intensity can be easily explained. As light intensity is increased, a larger number of photons are generated. More electron-hole pairs are then created at the surface of the $\gamma-\mathrm{Fe}_{2} \mathrm{O}_{3}$ NP. As a result, more $\mathrm{HO}^{\circ}$ radicals are generated. This larger concentration in $\mathrm{HO}^{\circ}$ radicals leads to a higher decomposition rate of MO.

\subsection{Stability and reusability of the catalysts}

Stability is an important property for an effective heterogeneous catalyst. One of the main limiting factors for the replacement of homogeneous Fenton catalysts by heterogeneous Fenton catalysts is the dissolution of a small part of iron ion during the depollution process, which may hinder the catalytic activity after several uses. The percentage of dissolved iron ions after $4 \mathrm{H}$ of reaction $\left(\mathrm{Fe}_{\mathrm{L}}\right)$ was measured for both catalysts, in the absence and in the presence of light, for the three compounds (see table S1, columns 9 and 10 in the ESI part). The results show that leached iron detected in the reaction solution is minimal, with $\mathrm{Fe}_{\mathrm{L}}$ less than $0.4 \%$, (except in the case of the photodegradation of MB by the MS catalyst, where $\mathrm{Fe}_{\mathrm{L}}$ is $0.7 \%$ ), which corresponds to iron concentrations in the supernatant of less than $1.3 \times 10^{-4} \mathrm{~mol}$ $\mathrm{L}^{-1}$. Remarkably, no major increase of the leaching is noted when the catalysts are submitted to light, while this phenomenon seems to be independent from the catalyst. The slightly larger $\mathrm{Fe}_{\mathrm{L}}$ observed for the MB pollutant with the MS catalyst may be due to the strong adsorption of this dye on this catalyst, which may remove additional iron from the surface of the $\gamma-\mathrm{Fe}_{2} \mathrm{O}_{3}$ $\mathrm{NP}$, once the products resulting from the degradation of MB are desorbed.[35] These results, combined with additional experiments showing the low catalytic activity of the supernatant after $4 \mathrm{~h}$ of reaction,[35] indicate that the contribution of the leached iron to the overall catalytic activity is weak. Moreover, the relatively low values of $\mathrm{Fe}_{\mathrm{L}}$ is indicative of the good chemical stability of the $\gamma-\mathrm{Fe}_{2} \mathrm{O}_{3} \mathrm{NP}$ during the reaction, which is required for the maintenance of their catalytic activity during several cycles. The stability of this catalyst is 
also confirmed by the TEM and SAED-TEM images of the free NP after one photo-Fenton test on the model pollutant $\mathrm{MO}$, and their dispersion in a $\mathrm{HNO}_{3} 10^{-3} \mathrm{~mol} \mathrm{~L}^{-1}$ aqueous solution (see figure S7 in the ESI). In comparison to the TEM image of the NP before catalysis (see figure 1-A), the TEM images of figure S7-A and B shows that the NP are characterized by similar sizes and morphologies. The TEM-SAED image of the sample (see figure S7-C) confirms that the nanoparticles are composed of $\gamma-\mathrm{Fe}_{2} \mathrm{O}_{3}$. The calibration of the SAED image allowed us to attribute the diffraction rings and spots to the interplanar spacings to the $\mathrm{d}_{440}$, $\mathrm{d}_{400}$, and $\mathrm{d}_{311}$ distances of the $\gamma-\mathrm{Fe}_{2} \mathrm{O}_{3}$ crystal lattice structure. Thus, the morphology and crystalline structure of the NP were not altered by the photocatalytic tests.

Reusability of a catalyst is of prime importance in assessing the practical application of a catalyst in water treatment. In practice, the reusability was only studied on the $\gamma-\mathrm{Fe}_{2} \mathrm{O}_{3} / \mathrm{SiO}_{2}$ MS since this catalyst can be perfectly removed from the effluent after few minutes of settling over a magnet (see fig. 1C). On the contrary, our attempts to remove the $\gamma-\mathrm{Fe}_{2} \mathrm{O}_{3} \mathrm{NP}$ by this method were unsuccessful (see fig. 1D), because of their high colloidal stability in water which also made difficult the other separation methods. The efficiency of the MS catalyst during five consecutive experiments was then investigated by regarding the decolorization of MO solutions. The catalytic tests were carried out for $4 \mathrm{~h}$, in the absence or in the presence of light. The results are shown in figure 5.
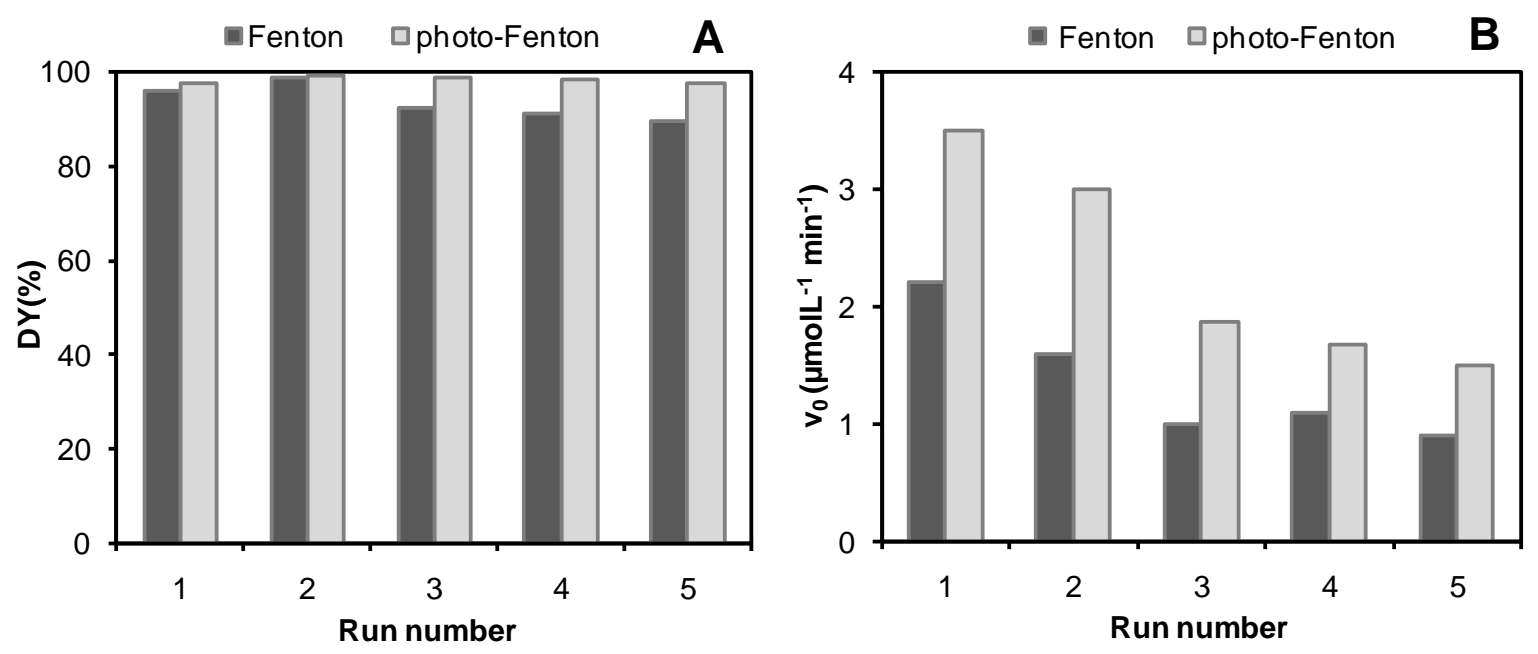

Fig. 5: Comparison of the reusability for five consecutive tests of the MS catalyst in the dark and under visible light, using MO as model pollutant. (A) Decolorization yields (DY) (taken at $\mathrm{t}=4 \mathrm{~h}$ and $\mathrm{t}=3 \mathrm{~h}$, for the Fenton, and the photo-Fenton processes, respectively). (B) Initial decolorization rates $\left(\mathrm{v}_{0}\right)$. 
As can be seen in figure 5, the MS catalyst maintained a significant catalytic activity for at least five uses. For the photo-Fenton process, the MS catalyst retained a good activity after five repeated experiments, with complete MO conversions (97.5-99\%), achieved within $3 \mathrm{~h}$ (see fig. 5A), although $\mathrm{v}_{0}$ was reduced from $57 \%$ (as shown in fig. 5B, $\mathrm{v}_{0}$ vary from $3.5 \mu \mathrm{mol}$ $\mathrm{L}^{-1} \min ^{-1}$ for the $1^{\text {st }}$ cycle, to $1.5 \mu \mathrm{mol} \mathrm{L}^{-1} \mathrm{~min}^{-1}$ for the $5^{\text {th }}$ cycle). Concerning the dark Fenton process, the catalyst also retained a relatively good activity, despite a slight decrease of the DY at $4 \mathrm{~h}$ from $98 \%$ to $90 \%$, and a reducing of $\mathrm{v}_{0}$ from $2.2 \mu \mathrm{mol} \mathrm{L} \mathrm{Lin}^{-1}$ for the first cycle to $0.9 \mu \mathrm{mol} \mathrm{L}{ }^{-1} \min ^{-1}$ for the $5^{\text {th }}$ cycle, representing $59 \%$ of decrease. For each cycle, thanks to the visible light irradiation, $\mathrm{v}_{0}$ is enhanced from a value oscillating between 1.5 and 1.9, indicating that the improvement factor due to light is almost constant. The moderate loss of activity as the catalyst is reused seems to be independent from the presence of the halogen lamp. This drop is not mainly due to the Fe leaching, taking into account the low amounts measured. Instead, we propose that the MS catalyst is progressively contaminated by some organic intermediates remaining strongly adsorbed on the iron oxide surface. For the tests in the dark, this has been qualitatively supported by the characterization of the catalyst after five cycles.[35] We have shown by SEM, $\mathrm{N}_{2}$ volumetry, X-ray diffraction and UV-vis-NIR spectroscopy that the internal structure of the microspheres remain unchanged, despite a slight modification of their external morphology. Nevertheless, characterization of the microspheres by IRTF spectroscopy and thermogravimetric analysis has evidenced the presence of small amounts of organics.

\section{Conclusion}

The present work aimed to study the effect of a visible light emitting halogen lamp on the Fenton degradation of model organic pollutants, in presence of a heterogeneous catalyst. The catalyst was constituted by dispersed maghemite $\left(\gamma-\mathrm{Fe}_{2} \mathrm{O}_{3}\right)$ nanoparticles (NP catalyst), or by the same nanoparticles encapsulated into microporous silica microspheres (MS catalyst). Both catalysts were characterized by a high magnetic susceptibility, and had therefore the potential to be easily recovered by a simple gradient of magnetic field. After their complete characterization, the catalysts were tested in the dark (Fenton Process), or under visible light illumination (photo-Fenton process), on three model organic pollutants, methylorange (MO), methylene blue (MB), and paranitrophenol (PNP). Much better catalytic activities were recorded in presence of visible light, whatever the catalyst, the pollutant tested, or the 
experimental conditions. The large range of conditions studied in this work enabled us to suggest a mechanism for the visible light photodegradation. Since the level of $v_{0}$ increase due to visible light is poorly influenced by the nature of the pollutant, we proposed that the first steps of the degradation are due to photogenerated electron-hole pairs in the band gap of the $\gamma-\mathrm{Fe}_{2} \mathrm{O}_{3}$ nanoparticles. Illumination led also to a strong improvement of the mineralization of the pollutant, which is essential for the application of this process in water treatment. In addition, good activities were obtained in conditions which are considered to be unfavorable for the Fenton-type processes. The good decolorization rates obtained at neutral $\mathrm{pH}$, at small amount of catalyst, or at small concentrations of $\mathrm{H}_{2} \mathrm{O}_{2}$, through the use of a simple halogen lamp, demonstrated the possibility to extent the area of efficiency of the heterogeneous Fenton-type processes, and to reduce the associated operating costs. Furthermore, the study on the effect of the light intensity on the catalytic activity of the NP proves that it may be possible to improve again the efficiency of the catalysts by using a lamp with a higher nominal power. Another positive aspect is the experiments of long-term stability which showed that MS catalyst retained almost all of its catalytic activity after five repeated experiments under visible light. The good stability of this catalyst was also confirmed by the low level of iron leaching. In conclusion, we believe that these good results, due to the simple use of a low-cost, widely available and easy-to-handle halogen lamp will make possible the use of magnetic heterogenous Fenton catalyst in industrial wastewater treatment, especially for niche applications where recovery of the catalyst is a critical point.

\section{Acknowledgements}

We wish to kindly thank Emmanuel Aubry, David Montero, Vincent Dupuis, and Patricia Beaunier for their technical support, Agnes Bée, Olivier Pluchery and Mohamed Salah Medjram for the fruitfull discussions. We equally acknowledge the scientific cooperation research programme PROFAS between France and Algeria for the financial support.

\section{References}

[1] R. Bauer, H. Fallmann, The photo-Fenton oxidation - a cheap and efficient wastewater treatment method, Res. Chem. Intermed., 23(1997) 341-354. 
[2] E. Neyens, J. Baeyens, A review of classic Fenton's peroxidation as an advanced oxidation technique, J. Hazard. Mater., 98(2003) 33-50.

[3] P.R. Gogate, A.B. Pandit, A review of imperative technologies for wastewater treatment i: oxidation technologies at ambient conditions, Adv. Environ. Res., 8 (2004) 501-551.

[4] A. Georgi, F.-D. Kopinke, Interaction of adsorption and catalytic reactions in water decontamination processes: part I. oxidation of organic contaminants with hydrogen peroxide catalyzed by activated carbon,Appl. Catal. B, 58 (2005) 9-18.

[5] P. Bautista, A. F. Mohedano, J. A. Casas, J. A. Zazo, J. J. Rodriguez, An overview of the application of Fenton oxidation to industrial wastewaters treatment, J. Chem. Technol. Biotechnol.,83 (2008) 1323-1338.

[6] M. R. Hoffmann, S. T. Martin, W. Choi, D. W. Bahnemann, Environmental applications of semi-conductor photocatalysis, Chem. Rev., 95 (1995) 69-96.

[7] S. Dong, J. Feng, M. Fan,Y. Pi, L. Hu, X. Han, M. Liu, J. Sun, J. Sun, Recent developments in heterogeneous photocatalytic water treatment using visible light-responsive photocatalysts: a review, RSC Adv., 5 (2015) 14610-14630.

[8] D. F. Ollis, E. Pelizzeti, N. Serpone, Heterogenous photocatalysis in the environment: application to water purification, in: N. Serpone, E. Pelizzetti (Eds.), Photocatalysis : Fundamentals and Application, Wiley, New York, 1989, pp. 603-637.

[9] M. A. Fox, M. T. Dulay, Hetereogenous photocatalysis, Chem. Rev. 93 (1993) 341-357.

[10] A. Fujishima, X. Zhang, D. A. Tryk, Heterogenous photocatalysis: from water photolysis to applications in environmental cleanup, Int. J. Hydrogen. Energ., 32 (2007)26642672.

[11] M. I. Litter, J. A. Navío, Comparison of the photocatalytic efficiency of $\mathrm{TiO}_{2}$, iron oxides and mixed Ti(IV)-Fe(III) oxides: photodegradation of oligocarboxylic acids, J. Photochem. Photobiol. A, 84 (1994) 184-193.

[12] J. Bandara, J. A. Mielczarski, A. Lopez, J. Kiwi, Sensitized degradation of chlorophenols on iron oxides induced by visible light. Comparison with titanium oxide. Appl. Catal. B, 34 (2001) 321-333.

[13] E. Casbeer, V. K. Sharma, X.-Z. Li, Synthesis and photocatalytic activity of ferrites under visible light : a review, Sep. Purif. Technol., 87 (2012) 1-14. 
[14] Y. Guichard, J. Schmit, C. Darne, L. Gate, M. Goutet, D. Rousset, O. Rastoix, R. Wrobel, O. Witschger, A. Martin, V. Fierro, S. Binet, Cytotoxicity and genotoxicity of nanosized and microsized titanium dioxide and iron oxide particles in syrian hamster embryo cells, Ann. Occup. Hyg., 56 (2012) 631-644.

[15] V. Srivastava, D. Gusain, Y. C. Sharma, Critical review of some widely used engineered nanoparticles, Ind. Eng. Chem. Res., 54 (2015) 6209-6233.

[16]L. M. Pastrana-Martínez, N. Pereira, R.A.Lima, J. L. Faria, H. T. Gomes , A. M.T. Silva, Degradation of diphenhydramine by photo-Fenton using magnetically recoverable iron oxide nanoparticles as catalyst, Chem. Eng. J., 261 (2015) 45-52.

[17] W. Song, M. Cheng, J. Ma, W. Ma, C. Chen, J. Zhao, Decomposition of hydrogen peroxide driven by photochemical cycling of iron species in clay, Environ. Sci. Technol., 40 (2006) 4782-4787.

[18] Z. Miao, S. Tao, Y. Wang, Y. Yu, C. Meng, Y. An, Hierarchically porous silica as an efficient catalyst carrier for high performance vis-light assisted Fenton degradation, Micropor. Mesopor.Mat., 176 (2013)178-185.

[19] B. Qiu, M. Xing, J. Zhang, Stöber-like method to synthesize ultralight, porous, stretchable $\mathrm{Fe}_{2} \mathrm{O}_{3}$ /graphene aerogels for excellent performance in photo-Fenton reaction and electrochemical capacitors , J. Mater. Chem. A, 3(2015) 12820-12827

[20] A.N. Soon, B.H. Hameed, Heterogeneous catalytic treatment of synthetic dyes in aqueous media using Fenton and photo-assisted Fenton Process, Desalination, 269 (2011) 116.

[21] W. Du, Q. Sun, X. Lv, Y. Xu, Enhanced activity of iron oxide dispersed on bentonite for the catalytic degradation of organic dye under visible light, Catal. Commun., 10 (2009) 18541858 .

[22] Q. Chen, P. Wu, Y. Li, N. Zhu, Z. Dang, Heterogeneous photo-Fenton photodegradation of Reactive Brilliant Orange X-GN over iron-pillared montmorillonite under visible irradiation, J. Hazard. Mater., 168 (2009) 901-908.

[23] X. Zhou, H. Yang, C. Wang, X. Mao, Y. Wang, Y. Yang, G. Liu, Visible light induced photocatalytic degradation of rhodamine B on one dimensional iron oxide particles, J. Phys. Chem. C, 114 (2010) 17051-17061. 
[24] Y. Zhao, F. Pan, H. Li, T. Niu, G. Xu, W. Chen, Facile synthesis of uniform $\alpha-\mathrm{Fe}_{2} \mathrm{O}_{3}$ crystals and their facet-dependent catalytic performance in the photo-Fenton reaction, J. Mater Chem. A, 1 (2013) 7242-7246.

[25] A. N. Soon, B. H. Hameed, Degradation of Acid Blue 29 in visible light radiation using iron modified mesoporous silica as heterogeneous photo-Fenton catalyst, Appl. Catal. A, 450 (2013) 96-105.

[26] Y. Tu, Y. Xiong, C. Descorme, L. Kong, S. Tian, Heterogeneous photo-Fenton oxidation of Acid Orange II over iron-sewage sludge derived carbon under visible irradiation, J. Chem. Technol. Biotechnol.,89 (2014) 544-551.

[27] Z. Wang, W. Ma, C. Chen, J. Zhao, Light-assisted decomposition of dyes over ironbearing clays in the presence of $\mathrm{H}_{2} \mathrm{O}_{2}$, J. Hazard. Mater., 168 (2009) 1246-1252.

[28] C.-H. Chen, Y.-H. Liang, W.-D. Zhang, $\mathrm{ZnFe}_{2} \mathrm{O}_{4} / \mathrm{MWCNTs}$ composite with enhanced photocatalytic activity under visible-light irradiation, J. Alloy Compd., 501 (2010) 168-172.

[29] X. Li, Y. Pi, L. Wu, Q. Xia, J. Wu, Z. Li, J. Xiao, Facilitation of the visible lightinduced Fenton-like excitation of $\mathrm{H}_{2} \mathrm{O}_{2}$ via heterojunction of $\mathrm{g}-\mathrm{C}_{3} \mathrm{~N}_{4} / \mathrm{NH}_{2}$-Iron terephthalate metal-organic framework for MB degradation, Appl. Catal. B, 202 (2017) 653-663.

[30] G. Moffat, R.A. Williams, C. Webb, R. Stirling, Selective separations in environmental and industrial processes using magnetic carrier technology, Miner. Eng., 7 (1994) 1039-1056.

[31] R. D. Ambashta, M. Sillanpää, Water purification using magnetic assistance: a review, J. Hazard. Mater., 180 (2010) 35-49.

[32] W. Wu, C. Jiang, V. A. L. Roy, Recent progress in magnetic iron oxide-semiconductor composite nanomaterials as promising photocatalysts, Nanoscale, 7 (2015) 38-58.

[33] B. Qiu, Y. Deng, M. Du ,M. Xing, J. Zhang, Ultradispersed Cobalt Ferrite Nanoparticles Assembled in Graphene Aerogel for Continuous Photo-Fenton Reaction and Enhanced Lithium Storage Performance, Sci. Rep.,6 (2016) 29099.

[34] B. A. Bolto, T. H. Spurling, Water purification with magnetic particles, Environ. Monit. Assess., 19 (1991)139-143.

[35] N. Ferroudj, J. Nzimoto, A. Davidson, D. Talbot, E. Briot, V. Dupuis, A. Bée, M. Salah Medjram, S. Abramson, Maghemite nanoparticles and maghemite/silica nnanocomposite 
microspheres as magnetic Fenton catalysts for the removal of water pollutants, Appl. Catal. B,136-137 (2013) 9-18.

[36] W. Wang, M. Zhou, Q. Mao, J. Yue, X. Wang, Novel NaY zeolite-supported nanoscale zero-valent iron as an efficient heterogeneous Fenton catalyst, Catal. Commun., 11 (2010) 937-941.

[37] R.Massart , Preparation of aqueousmagneticliquids in alkaline and acidic media, IEEE Trans.Magn ,17 (1981) 1247-1248.

[38] V.Cabuil, Ferrofluides à base de maghémite : synthèse, propriétés physicochimiques et magnéto-optiques, Ph.D.Thesis, University Pierre et Marie Curie, Paris, 1987.

[39] F.A.Tourinho, R.Franck, R.Massart, Aqueous ferrofluids based on manganese and cobalt ferrites, J. Mater. Sci., 25 (1990) 3249-3254.

[40] N. Andersson, R.W. Corkery, P.C.A. Alberius, One-pot synthesis of well ordered mesoporous magnetic carriers, J. Mater. Chem, 17 (2007) 2700-2705.

[41] İ Gulkaya, G. A. Surucu, F. B. Dilek, Importance of $\mathrm{H}_{2} \mathrm{O}_{2} / \mathrm{Fe}^{2+}$ ratio in Fenton's treatment of a carpet dyeing wastetwater, J. Hazard. Mater. B, 136 (2006),763-769.

[42] C. S. Williams, O. A. Becklund, Optics: a short course for engineers and scientists, Wiley-Interscience, New York, 1972.

[43] J.-C. Bacri, R. Perzynski, D. Salin, V. Cabuil, R. Massart, Magnetic colloidal properties of ionic ferrofluids, J. Magn. Magn. Mater., 62 (1986) 36-46.

[44] M. M. Dubinin, V. A. Astakhov, Description of adsorption equilibria of vapors on zeolites over wide ranges of temperature and pressure, Adv. Chem. Ser., 102 (1971) 69-85.

[45] J. Feng, X. Hu, P. L. Yue, Decoloration and mineralization of Orange II by using a bentonite clay-based Fe nanocomposite film as a heterogenous photo-Fenton catalyst, Water Res., 39 ( 2005) 89-96.

[46] G. Zhan , H. C. Zeng, Charge-Switchable Integrated Nanocatalysts for SubstrateSelective Degradation in Advanced Oxidation Processes, Chem. Mater.,28 (2016) $4572-4582$.

[47] I. Arslan-Alaton, Degradation of a commercial textile biocide with advanced oxidation processes and ozone, J. Environ. Manage, 82 (2007) 145-154. 
[48] J. Bandara, U. Klehm, J. Kiwi, Raschig Rings- $\mathrm{Fe}_{2} \mathrm{O}_{3}$ composite photocatalyst activate in the degradation of 4-chlorophenol and Orange II under daylight irradiation, Appl. Catal. B, 76 (2007) 73-81.

[49] S.-P. Sun, A. T. Lemley, p-Nitrophenol degradation by a heterogeneous Fenton-like reaction on nano-magnetite: Process Optimization, kinetics, and degradation pathways, J. Mol. Catal. A, 349 (2011)71-79.

[50] F. Martinez, G. Calleja, J. A. Melero, R. Molina, Iron species incorporated over different silica supports for the heterogeneous photo-Fenton oxidation of phenol, Appl. Catal. B, 70 (2007) 452-460.

[51] W. G. Barb, J. H. Baxendale, P. George, K. R. Hargrave, Reactions of ferrous and ferric ions with hydrogen peroxide : Part I the ferrous ions reaction, Tans. Faraday Soc., 47 (1951) 591-616.

[52] B. M. Voelker, W. P. Kwan, Rates of hydroxyl radical generation and organic compound oxidation in mineral-catalyzed Fenton-like systems, Environ. Sci. Technol., 37 (2003) 11501158.

[53] W. Feng, D. Nansheng, Photochemistry of hydrolytic iron (III) species and photoinduced degradation of organic compounds. A minireview, Chemosphere, 41 (2000) 1137-1147.

[54] K. Wu, Y. Xie, J. Zhao, H. Hidaka, Photo-Fenton degradation of a dye under visible light irradiation, J. Mol. Catal. A: Chem., 144 (1999) 77-84.

[55] M. Cheng, W. Song, W. Ma, C. Chen, J. Zhao, J. Lin, H. Zhu, Catalytic activity of iron species in layered clays for photodegradation of organic dyes under visible irradiation, Appl. Catal. B, 77 (2008) 355-363. 